\title{
Deep Bed lodine Sorbent Testing FY 2011 Report
}

Nick Soelberg

Tony Watson

August 2011

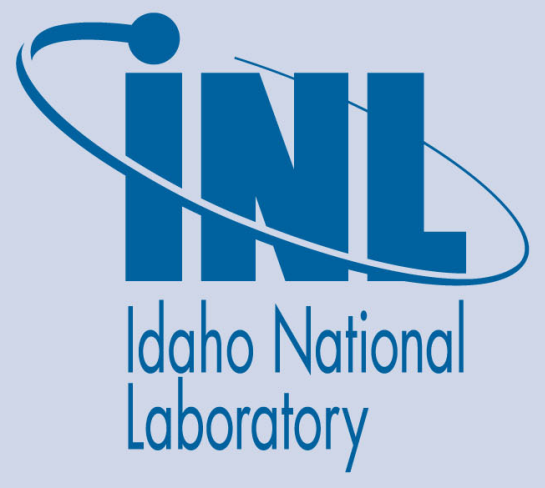

The INL is a U.S. Department of Energy National Laboratory operated by Battelle Energy Alliance 
INL/EXT-11-23191

FCRD-SWF-2011-000316

\title{
Deep Bed lodine Sorbent Testing FY 2011 Report
}

\author{
Nick Soelberg \\ Tony Watson
}

August 2011

\author{
Idaho National Laboratory \\ Fuel Cycle Research \& Development \\ Idaho Falls, Idaho 83415
}

http://www.inl.gov

Prepared for the

U.S. Department of Energy

Office of Nuclear Energy

Under DOE Idaho Operations Office

Contract DE-AC07-05ID14517 


\section{DISCLAIMER}

This information was prepared as an account of work sponsored by an agency of the U.S. Government. Neither the U.S. Government nor any agency thereof, nor any of their employees, makes any warranty, expressed or implied, or assumes any legal liability or responsibility for the accuracy, completeness, or usefulness, of any information, apparatus, product, or process disclosed, or represents that its use would not infringe privately owned rights. References herein to any specific commercial product, process, or service by trade name, trade mark, manufacturer, or otherwise, does not necessarily constitute or imply its endorsement, recommendation, or favoring by the U.S. Government or any agency thereof. The views and opinions of authors expressed herein do not necessarily state or reflect those of the U.S. Government or any agency thereof. 


\section{ACKNOWLEDGEMENTS}

We acknowledge of others helped guide or perform iodine sorption testing this year. Jack Law of the Idaho National Laboratory (INL) Aqueous Separations and Radiochemistry Department and the Department of Energy Fuel Cycle Research and Development Program Separations and Waste Forms Campaign, and Bob Jubin of the Oak Ridge National Laboratory (ORNL), and the leader of the Separations and Waste Forms Campaign Off-gas Sigma Team, provided programmatic and technical direction. Sorbents tested this year were provided by Bob Jubin's team at the ORNL, and by Tina Nenoff's team that included Yifeng Wang and Ernie Tellez, all at Sandia National Laboratories (SNL) and members of the Off-gas Sigma Team.

Daryl Haefner of the INL Environmental Engineering and Technology Department, and Veronica Rutledge of the INL Aqueous Separations and Radiochemistry Department, helped in test planning test performance at key times during the year. Duane Ball and Paula Hahn of the INL Chemistry and Radiation Measurement Department performed iodine sample analyses. Duane "bent over backwards" to help at a time when doing so was very difficult - before and after back surgery. We were glad to rely on the high quality of Duane's and Paula's measurements. Michael Jones of the INL Nuclear Materials Characterization Department provided valuable gas chromatography measurement support at times when we needed it the most.

Sharna Rossberg of the INL provided valuable assistance in preparing and reviewing this report. 
Deep Bed lodine Sorbent Testing FY 2011 Report

This page blank 


\section{SUMMARY}

Nuclear fission results in the production of fission products (FPs) and activation products that increasingly interfere with the fission process as their concentrations increase. Some of these fission and activation products tend to evolve in gaseous species during used nuclear fuel reprocessing. Research to develop and demonstrate Modified Open Cycle and Full Recycle nuclear fuel cycle options needs to show that fission and activation products that evolve as gaseous species can be controlled during used fuel reprocessing to meet air emission limits and protect the environment and the public.

Analyses have shown that I129, due to its radioactivity, high potential mobility in the environment, and high longevity (half life of 15.7 million years), can require control efficiencies of up to 1,000x or higher to meet regulatory emission limits. Rightly so, the control of iodine emissions during used fuel reprocessing is an important issue. The Department of Energy (DOE) Fuel Cycle Research and Development (FCRD) Program has supported research and development on iodine control and iodine waste forms for the past several years. Iodine capture is an important aspect of the Separations and Waste Forms Campaign Off-gas Sigma Team (Jubin 2011, Pantano 2011).

Deep-bed iodine sorption testing has a unique and important role in the Off-gas Sigma Team iodine research program. The deep bed testing can:

- Measure sorbent performance under more life-like (but admittedly still idealized) sorption configurations and operating conditions

- Measure sorption efficiencies

- Measure capacity of sorbents up to breakthrough

- Estimate mass transfer zone depths

- Generate data for isotherms and dynamic modeling

- Produce greater-than-gram-quantities of iodine-laden sorbent for confirming Ag and iodine loadings and waste form studies.

\section{Pre-2011 Deep Bed Test Results}

Deep-bed iodine sorbent testing was started at the INL in the year 2009 and has continued through this year (Haefner 2009, Haefner 2010). Accomplishments prior to FY 2011 include:

- Designed and build bench-scale test system

- Developed and applied analytical techniques

- Initial tests showed iodine decontamination factors (DFs) of 1,000-10,000, exceeding target levels $(>100-1,000)$

- Used diatomic iodine in initial tests; added methyl iodide in year 2

- Showed that (under test conditions) the order of magnitude of DFs was not significantly affected by the gas matrix $\left(\mathrm{H}_{2} \mathrm{O}, \mathrm{NO}_{\mathrm{x}}\right.$, and $\mathrm{N}_{2}$ (versus air).

\section{Remaining Issues and Data Gaps}

While the understanding of iodine sorbent performance has progressed under the Off-gas Sigma team focus, some issues and data gaps remain. These include:

- Understanding of adsorption mechanisms

- Performance information (control efficiency, capacity, MTZ, etc.) for novel new sorbents 
- Data gaps such as isotherm data for previously tested sorbents

- Data for dynamic iodine sorption modeling

- Waste form performance data, incorporating the conversion or use of the iodine sorbent in the waste form.

\section{FY 2011 Deep Bed Testing}

The objectives of the FY 2011 deep bed iodine sorbent testing are:

- Evaluate sorbents for iodine capture under various conditions of gas compositions and operating temperature (determine sorption efficiencies, capacities, and mass transfer zone depths)

- Generate data for dynamic iodine sorption modeling.

Tests proceeded to the extent of available funding and time. Not included in the scope of this year's testing were:

- Tests designed to measure iodine sorption and sorbent performance for most separations process gas streams besides the dissolver off-gas

- Tests for evaluating iodine capture and sorbent performance for gas streams from electrochemical processing.

\section{FY 2011 DEEP BED IODINE SORBENT TEST RESULTS}

Three tests performed this fiscal year on silver zeolite light phase (AgZ-LP) sorbent are reported here. Additional tests are still in progress and can be reported in a revision of this report or a future report.

Each test consisted of (a) flowing a synthetic blend of gases designed to be similar to an aqueous dissolver off-gas stream over the sorbent contained in three separate bed segments in series, (b) measuring each bed inlet and outlet gas concentrations of iodine and methyl iodide (the two surrogates of iodine gas species considered most representative of iodine species expected in dissolver off-gas), (c) operating for a long enough time to achieve breakthrough of the iodine species from at least one (preferably the first two) bed segments, and (d) post-test purging with pure $\mathrm{N}_{2}$ to drive loosely or physisorbed iodine species off of the sorbent. Post-test calculations determine the control efficiencies for each bed, iodine loadings on the sorbent, and mass transfer zone depths. Portions of the iodine-laden sorbent from the first bed of two of the tests have been shipped to SNL for waste form studies.

Over the past three years, we have explored a full range of inlet iodine and methyl iodide concentrations ranging from $\sim 100 \mathrm{ppb}$ to $\sim 100 \mathrm{ppm}$ levels, and shown adequate control efficiencies within a bed depth as shallow as 2 inches for lower concentrations and 4 inches for higher concentrations, for the AgZ-type sorbents. We are now performing a limited number of tests in the NC-77 sorbent from SNL. Then we plan to continue to (a) fill in data gaps needed for isotherms and dynamic sorbent modeling, and (b) test the performance of additional sorbents under development. 


\section{TABLE OF CONTENTS}

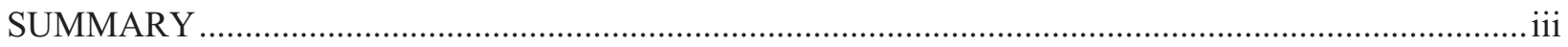

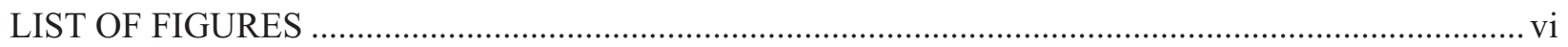

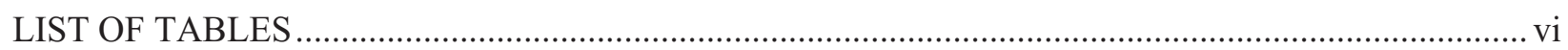

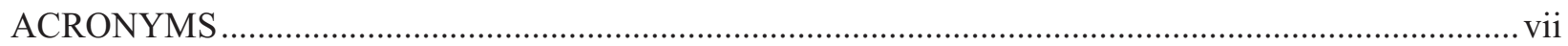

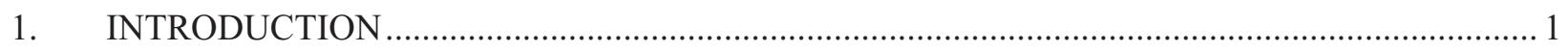

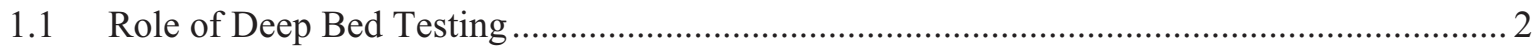

1.2 Summary of Pre-2011 Deep Bed Test Results .............................................................. 3

1.3 Remaining Issues and Data Gaps ............................................................................... 4

1.4 Objectives and Scope of FY 2011 Deep Bed Testing ...................................................... 4

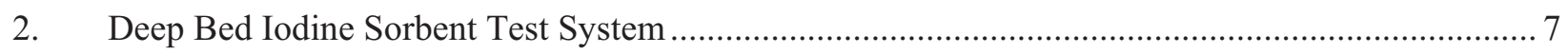

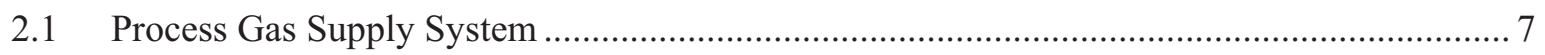

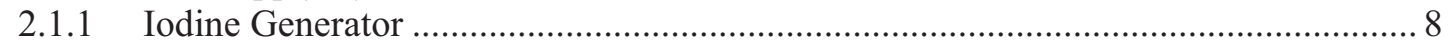

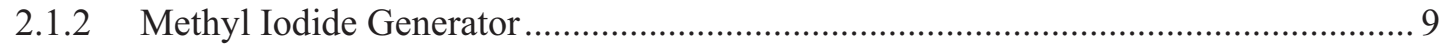

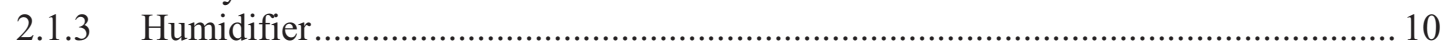

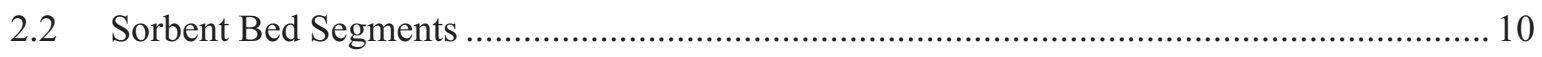

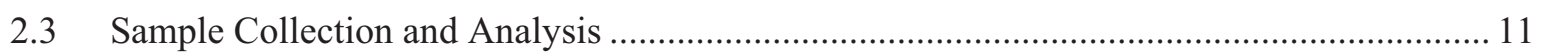

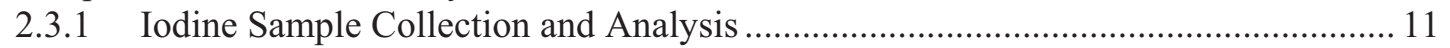

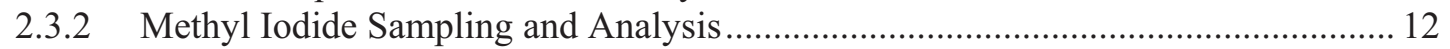

2.3.3 Sampling and Analysis Lessons Learned.............................................................. 13

$2.4 \quad$ Recommendations for Future Analyses ......................................................................... 13

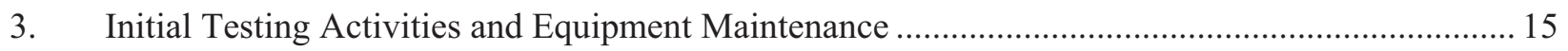

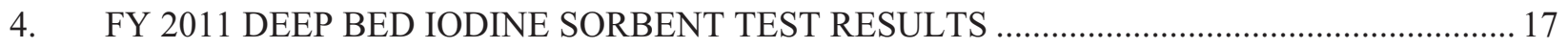

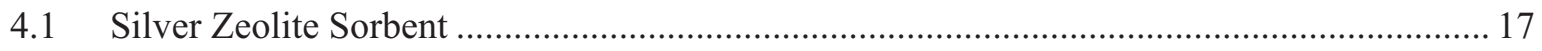

4.2 Sorbent Appearance, Calculated Bed Loading, Purge Results ............................................ 17

4.3 Test 1 Iodine and Methyl Iodide Sorption Results......................................................... 23

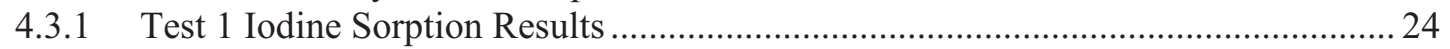

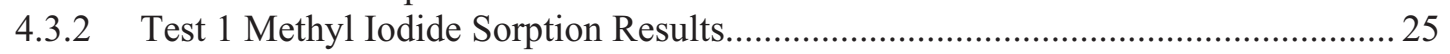

4.4 Test 2 Iodine and Methyl Iodide Sorption Results......................................................... 26

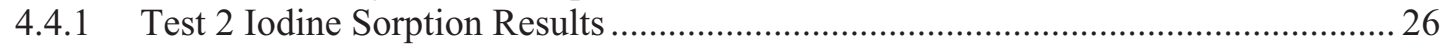

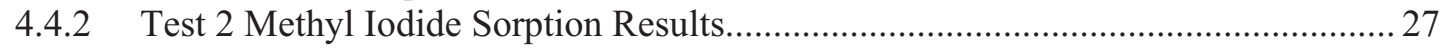

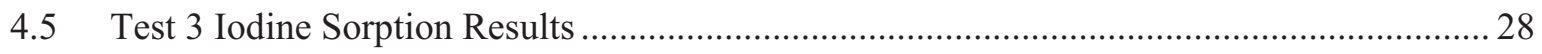

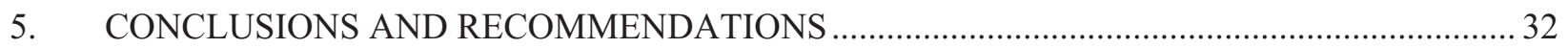

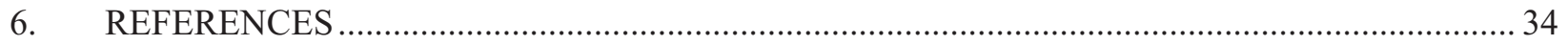




\section{LIST OF FIGURES}

Figure 1-1. First-order thermal fission yield of various uranium, neptunium, plutonium isotopes............. 1

Figure 1-2. Gaseous emissions control efficiencies for compliance to U.S. regulatory air emission

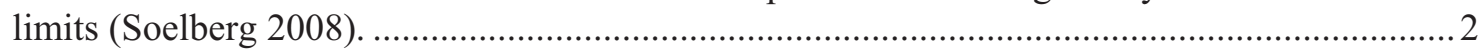

Figure 1-3. Iodine control and waste form research and development interfaces within the Off-

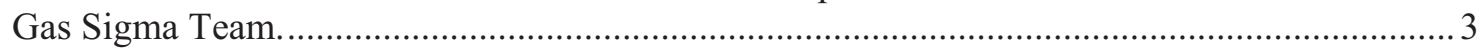

Figure 1-4. Illustration of potential off-gas streams from an aqueous separations plant......................... 5

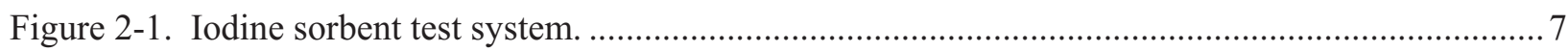

Figure 2-2. View of the iodine bubblers, the permeation tube iodine or methyl iodide generator,

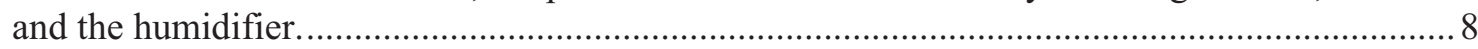

Figure 2-3. First, second, and third generation iodine generators for high iodine flowrates. ................... 9

Figure 2-4. Detail of the sorbent beds. At times, only 3 instead of all 4 beds are used......................... 10

Figure 2-5. Configuration of the sorbent beds inside the temperature-controlled oven........................... 11

Figure 2-6. On-line GC for methyl iodide analysis. The brown sheathed heated sample enters the

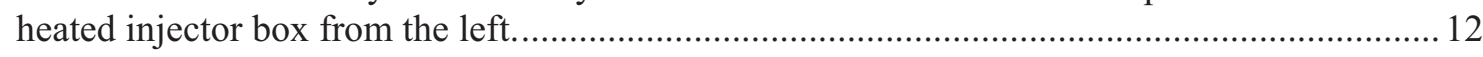

Figure 2-7. The 6-port injector that controls injections of sample gas into the GC. The sample is the stainless steel tubing loop on the right side of the injector. ................................................. 12

Figure 4-1. Fresh AgZ-LP sorbent loaded into the 3 sorbent bed segments...........................................22

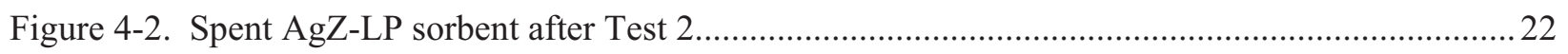

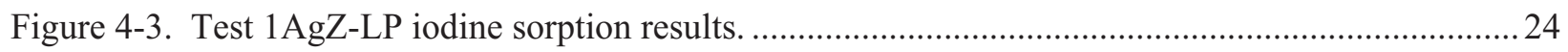

Figure 4-4. Mass transfer zone, the zone in the sorbent bed were sorption occurs the most and gas-phase and sorbent-phase concentrations of the sorbate are rapidly changing....................25

Figure 4-5. Test 1AgZ-LP methyl iodide sorption results. ................................................................ 26

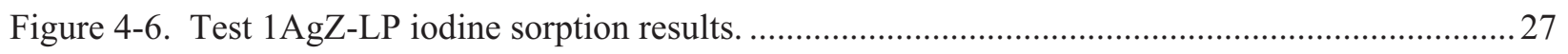

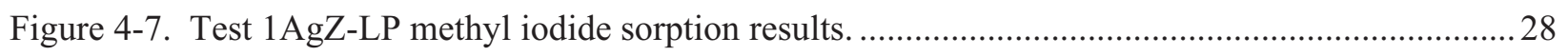

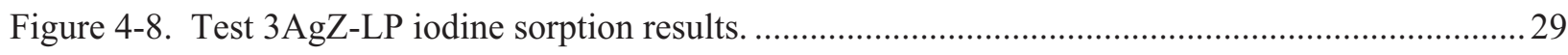

\section{LIST OF TABLES}

Table 4-1. First set of iodine sorbent tests performed in FY 2011 ...................................................... 18

Table 4-2. Surface area measurements for the AgZ Natural sorbent. ...................................................20

Table 4-3. Surface area measurements for the AgZ Light Phase sorbent...............................................2 21 


\section{ACRONYMS}

$\begin{array}{ll}\text { AgZ-LP } & \text { silver zeolite light phase } \\ \text { BET } & \text { Brunauer, Emmett, and Teller } \\ \text { DF } & \text { decontamination factors } \\ \text { DOE } & \text { Department of Energy } \\ \text { DVB } & \text { divinylbenzene } \\ \text { FCRD } & \text { Fuel Cycle Research and Development } \\ \text { FP } & \text { fission products } \\ \text { FY } & \text { fiscal year } \\ \text { GC } & \text { gas chromatograph } \\ \text { INL } & \text { Idaho National Laboratory } \\ \text { ICP-MS } & \text { inductively coupled plasma mass spectrometry } \\ \text { MS } & \text { mass spectrometry } \\ \text { MTZ } & \text { mass transfer zone } \\ \text { ORNL } & \text { Oak Ridge National Laboratory } \\ \text { SNL } & \text { Sandia National Laboratory }\end{array}$


This page blank 


\section{INTRODUCTION}

Nuclear fission results in the production of fission products (FPs) and activation products that increasingly interfere with the fission process as their concentrations increase. Modified Open Cycle and Full Recycle nuclear fuel cycle options include reprocessing used nuclear fuel to remove and discard fission and activation products so that remaining, purified fertile and fissile isotopes in the used fuel can be recycled into new fuel for continued nuclear power generation.

Figure 1-1 shows typical yields for fission products from nuclear fission of a variety of fertile and fissile isotopes during thermal fission. Fission products produced in greatest quantities are those with atomic masses between about 80-160, and especially those with atomic masses between about 90-105 and $130-150$.

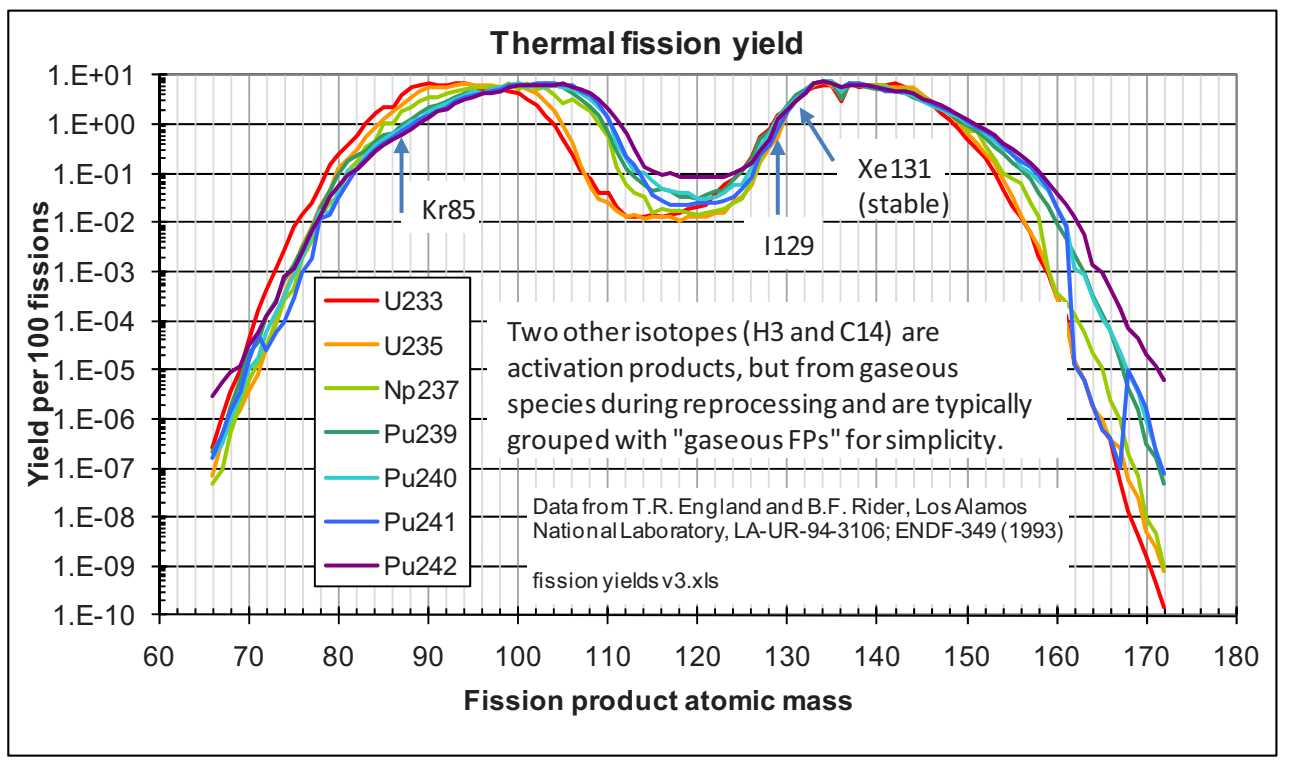

Figure 1-1. First-order thermal fission yield of various uranium, neptunium, and plutonium isotopes.

Certain fission products within these ranges of high yield are gaseous or form gaseous species in the reactor fuel or during typical reprocessing conditions. These include isotopes of noble gases $\mathrm{Kr}$ and $\mathrm{Xe}$, and the halogen iodine. (Two other isotopes, $\mathrm{H} 3$ and $\mathrm{C} 14$, are not fission products but are activation products that are also produced during irradiation in quantities sufficient enough to be significant.) The radioactive isotopes $\mathrm{H} 3, \mathrm{C} 14, \mathrm{Kr} 85, \mathrm{I} 129$ are of concern in nuclear fuel cycles because of their radioactivity and their tendency to exist in or form gaseous species, which can cause them to evolve to the atmosphere unless they are captured during reprocessing.

Atmospheric emissions of these gaseous fission products are regulated in the U.S. to levels that prevent harm to the environment, workers, and the public. Analyses have been done to assess, based on their relative amounts in used fuels, what control efficiencies are needed during used fuel reprocessing to comply with the applicable regulatory limits (Soelberg 2008, Jubin 2011).

These analyses show that I129, due to its radioactivity, high potential mobility in the environment, and high longevity (half life of 15.7 million years), can require control efficiencies of up to 1,000x or higher to meet regulatory emission limits (Figure 1-2). I129 emissions are regulated on the basis of a total emission limit for the entire fuel cycle in 40 CFR 190 (EPA 2010a) (which results in a constant control efficiency requirement of about 1,000 for a safety factor of about 10x below the regulatory limit). I129 emissions are also regulated on the basis of ambient air concentration limits and radioactive dose limits to the public in 10 CFR 20 (NRC 2011) and 40 CFR 61 (EPA 2010b) (which results in a control efficiency limit that increases from below 1,000x to over 10,000x depending on a reasonable reprocessing 
facility throughput between 100 and 1,000 metric tons of initial heavy metal per year (tIHM/yr). The hypothetical air dispersion and dose calculations in Soelberg (2008) indicate that, among the radioactive gaseous FPs I129, H3, Kr85, and C14, uncontrolled iodine emissions would cause about $79 \%$ of the total dose - hence the high dose-based I129 control limit compared to H3, Kr85, and C14.

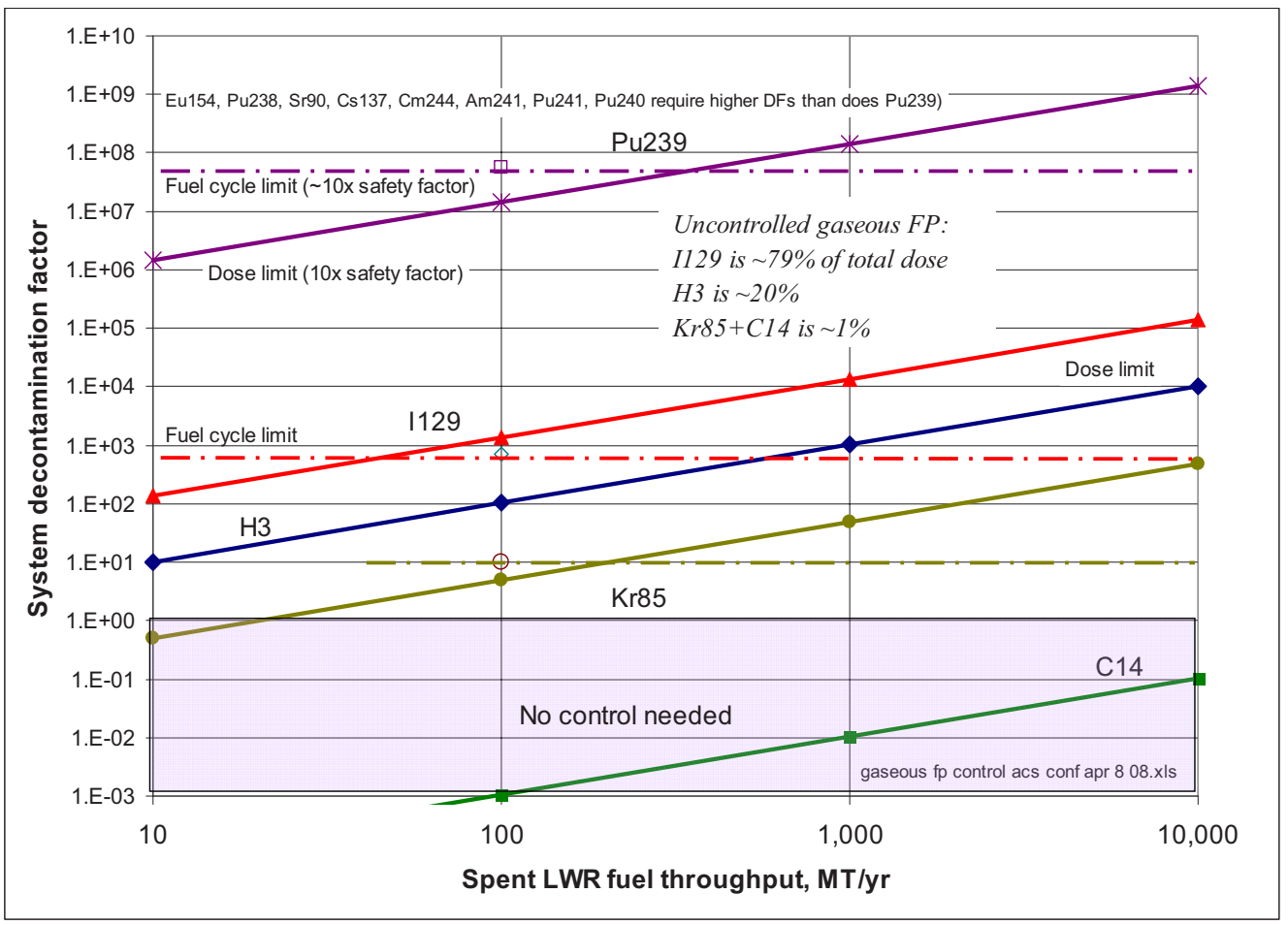

Figure 1-2. Gaseous emissions control efficiencies for compliance to U.S. regulatory air emission limits (Soelberg 2008).

Rightly so, the control of iodine emissions during used fuel reprocessing is an important issue. The Department of Energy (DOE) Fuel Cycle Research and Development (FCRD) Program has supported research and development on iodine control and iodine waste forms for the past several years. Iodine capture is an important aspect of the Separations and Waste Forms Campaign Off-gas Sigma Team (Jubin 2011, Pantano 2011).

\subsection{Role of Deep Bed Testing}

The Offgas Sigma Team was formed in 2009 within the Separations and Waste Forms Campaign to establish a team of researchers from different DOE sites to focus on research and development for emissions control and waste forms for gaseous radionuclides. Figure 1-3 shows iodine control and waste form research areas and interfaces within the Off-gas Sigma Team. Deep-bed iodine sorption testing has a unique and important role in the Off-gas Sigma Team iodine research program, recognized in the Fiscal Year (FY) 2011 Off-gas Sigma Team Peer Review (Pantano 2011). The deep bed testing can:

- Measure sorbent performance under more life-like (but admittedly still idealized) sorption configurations and operating conditions

- Measure sorption efficiencies

- Measure capacity of sorbents up to breakthrough

- Estimate mass transfer zone depths 
- Generate data for isotherms and dynamic modeling

- Produce > gram-quantities of iodine-laden sorbent for confirming Ag and iodine loadings and waste form studies

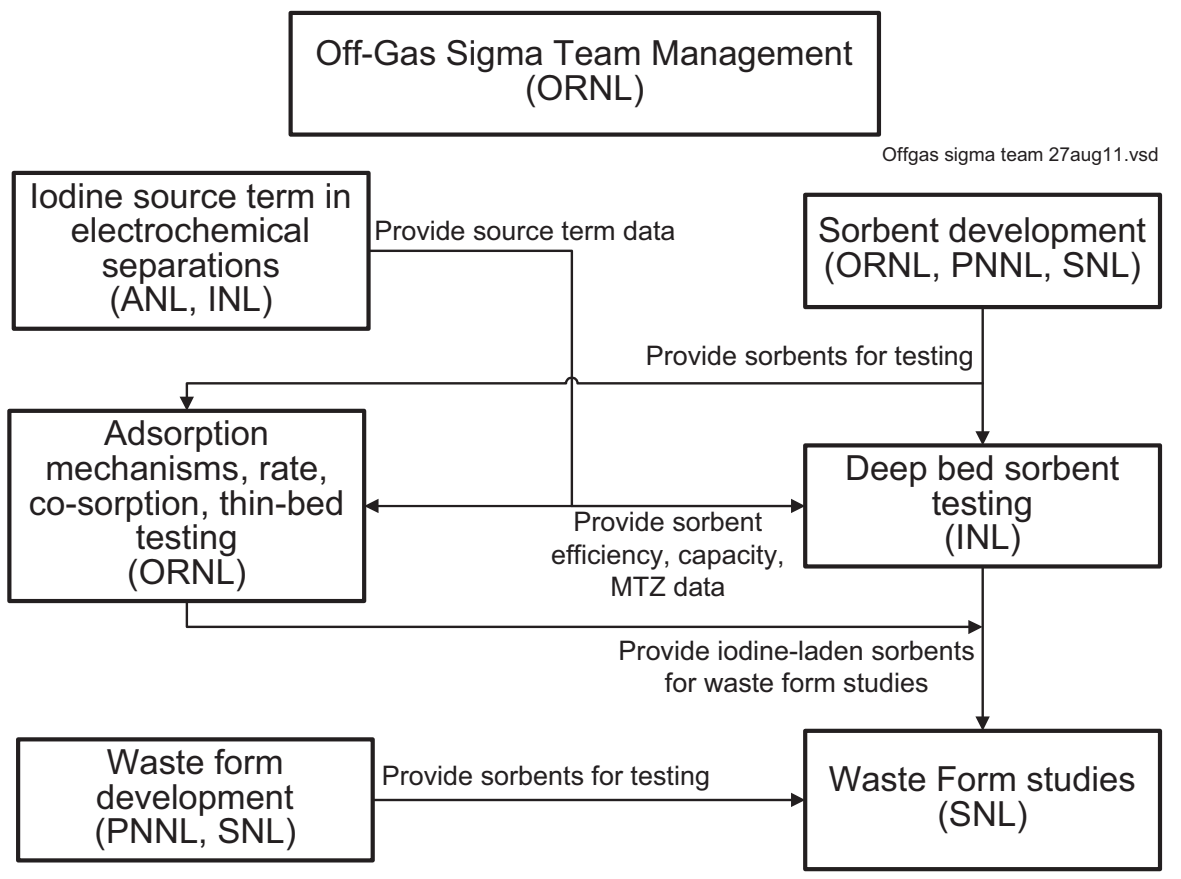

Figure 1-3. Iodine control and waste form research and development interfaces within the Off-Gas Sigma Team.

\subsection{Summary of Pre-2011 Deep Bed Test Results}

Deep-bed iodine sorbent testing was started at the INL in the year 2009 and has continued through this year (Haefner 2009, Haefner 2010). Accomplishments prior to FY 2011 include:

- Designed and build bench-scale test system

- Developed and applied analytical techniques

- Resolved handling techniques to prevent contamination, enabling measurement of up to $10,000 \mathrm{x}$ variations in measured values and low detection limits

- Initial tests showed iodine DFs of 1,000 - 10,000, exceeding target levels (>100-1,000)

- Used diatomic iodine in initial tests; added methyl iodide in year 2

- Showed that (under test conditions) the order of magnitude of DFs was not significantly affected by the gas matrix $\left(\mathrm{H}_{2} \mathrm{O}, \mathrm{NO}_{\mathrm{x}}\right.$, and $\mathrm{N}_{2}$ (versus air)

- But data was not yet sufficient to determine if capacity or mass transfer zone (MTZ) are impacted, or if smaller $(+/-10 \%)$ impacts on DFs occur from gas matrix effects, especially under longer actual operation

- Initially tested sorbents were all Ag mordenites - IONEX AG900 procured commercially and silver-reduced Ag mordenite from ORNL. 


\subsection{Remaining Issues and Data Gaps}

While the understanding of iodine sorbent performance has progressed under the Off-gas Sigma team focus, some issues and data gaps remain. These include:

- Understanding of adsorption mechanisms

- Performance information (control efficiency, capacity, MTZ, etc.) for novel new sorbents

- Data gaps such as isotherm data for previously tested sorbents

- Data for dynamic iodine sorption modeling

- Waste form performance data, incorporating the conversion or use of the iodine sorbent in the waste form

The need for continued deep bed iodine sorption testing to help address these was emphasized by the FY 2011 Sigma Team (Pantano 2011): "We strongly support the study on iodine capture on deep beds."

\subsection{Objectives and Scope of FY 2011 Deep Bed Testing}

The objectives of the FY 2011 deep bed iodine sorbent testing are:

- Evaluate sorbents for iodine capture under various conditions of gas compositions and operating temperature

- Determine sorption efficiencies

- Determine sorption capacities (only when run to breakthrough - ppb-level tests will not determine capacity)

- Estimate mass transfer zone depths (only when run to breakthrough)

- Generate data for dynamic iodine sorption modeling.

A test plan was prepared in early FY 2011 (Soelberg 2010), and has been the guiding document for work performed this year. The scope of testing includes performing tests using selected sorbents provided by the Off-gas Sigma Team. Tests were generally performed for a long enough duration so that breakthrough occurred. These breakthrough tests enabled the determination of sorption efficiencies up to the time of breakthrough, and sorbent capacities at the time breakthrough (which is the practical limit to the sorbent capacity, even though sorption is expected to continue in the "spent" sorbent after breakthrough).

Two different iodine species were used in various tests - diatomic $\mathrm{I}_{2}$ (which is a likely iodine species in an aqueous dissolver off-gas) and methyl iodide $\left(\mathrm{CH}_{3} \mathrm{I}\right.$, which is used as a surrogate for a potential variety of organic iodide species. All work was performed in compliance to work control documentation that was updated for this year's work, to ensure data quality, worker safety, environmental protection, and regulatory compliance during testing (INL 2011).

The tests were designed to primarily demonstrate the sorbent performance for capturing iodine species in hypothetical aqueous dissolver off-gas, recognizing that a variety of other gas streams could exist in an aqueous separations process; some of which would have considerably different compositions and flowrates (Figure 1-4). 


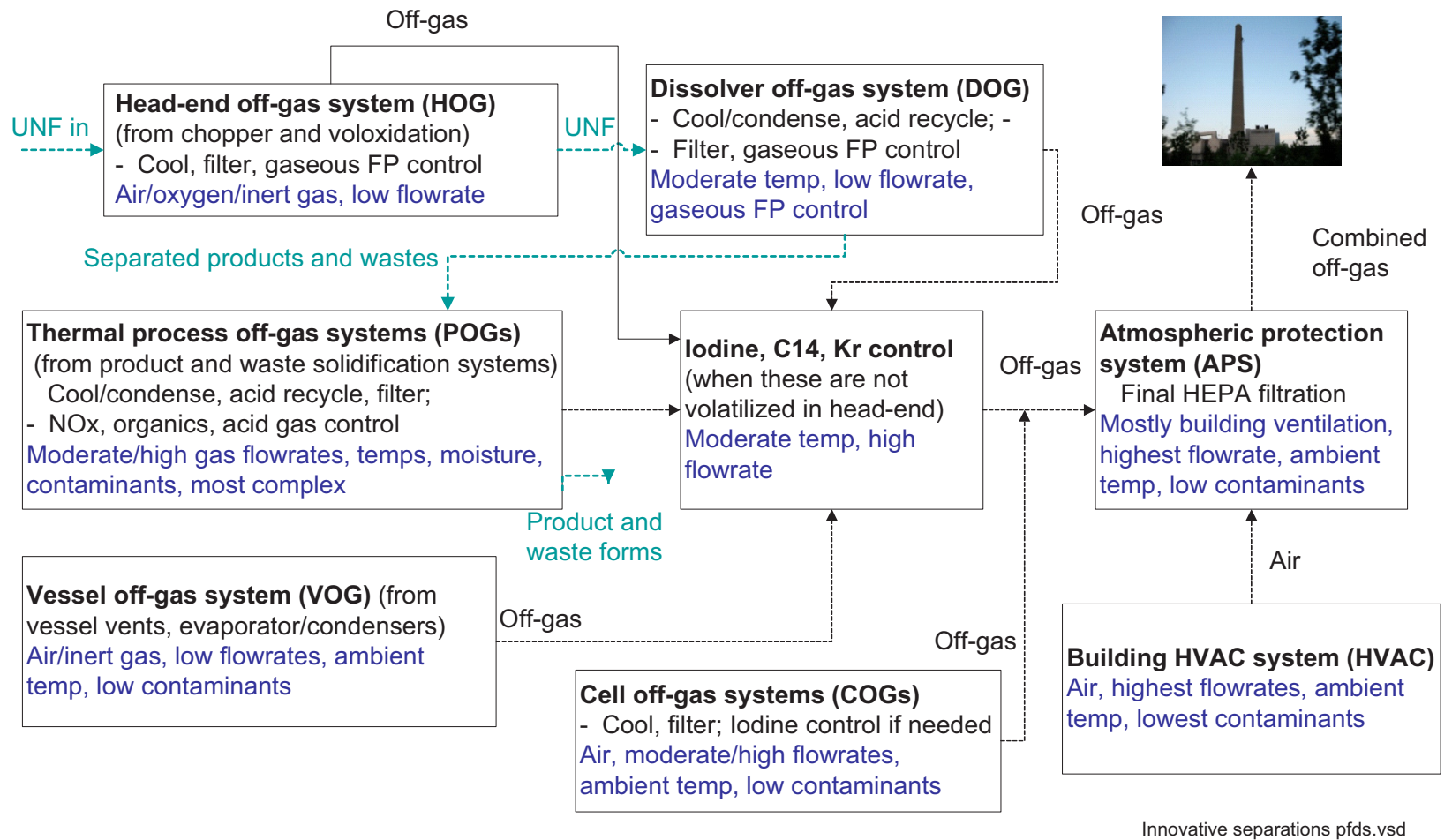

Figure 1-4. Illustration of potential off-gas streams from an aqueous separations plant.

Tests proceeded to the extent of available funding and time. Not included in the scope of this year's testing were:

- Tests designed to measure iodine sorption and sorbent performance for most separations process gas streams besides the dissolver off-gas

- Tests for evaluating iodine capture and sorbent performance for gas streams from electrochemical processing. 
This page blank 


\section{DEEP BED IODINE SORBENT TEST SYSTEM}

Figure 2-1 shows a process diagram for the iodine test system. The main components are the:

- Process gas supply and blending system, which supplies gases from gas cylinders, iodine gas species generators, and a humidifier

- Multiple sorbent bed system inside a heated oven

- Process gas bypass

- Inlet and bed segment outlet gas sampling system.

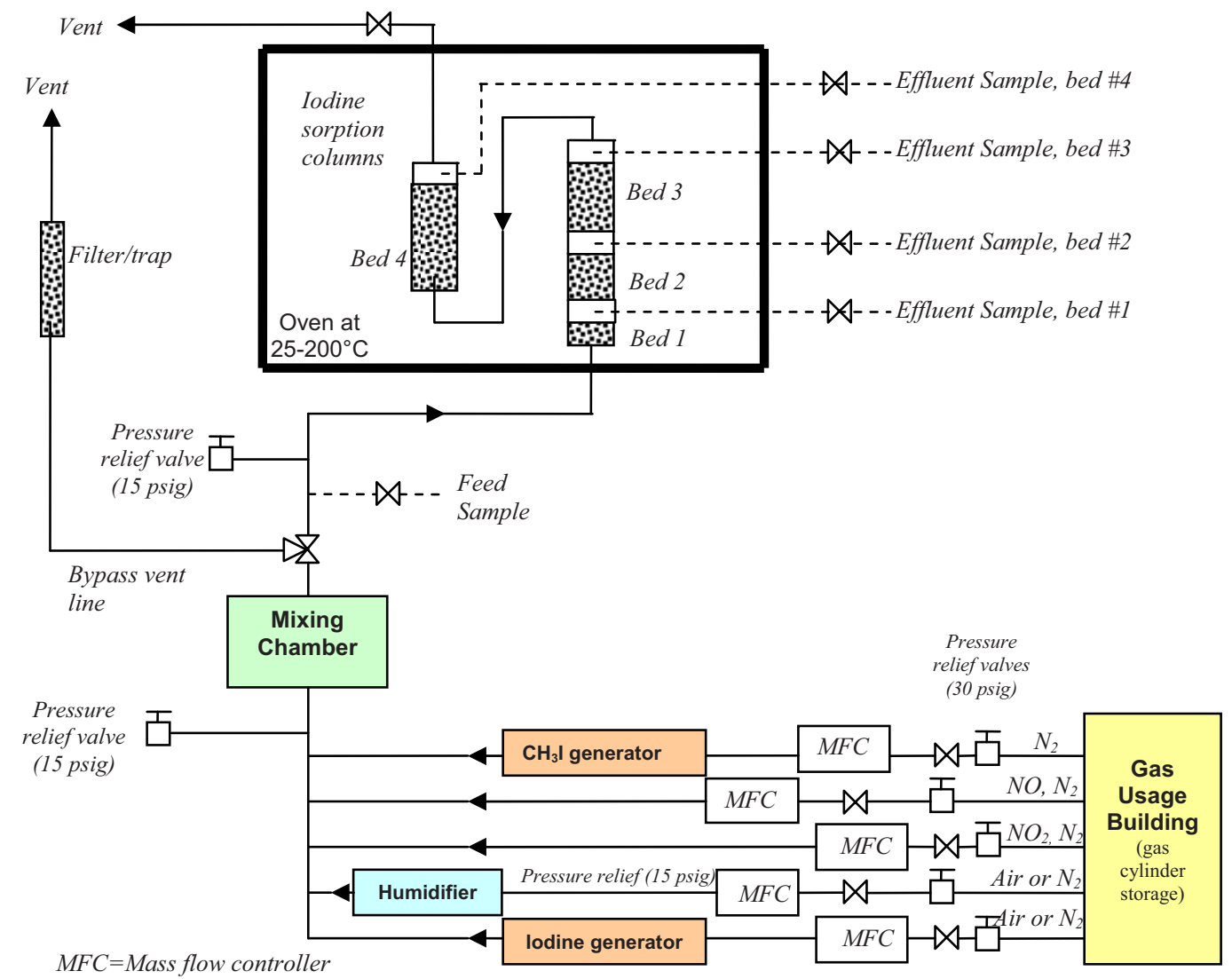

Figure 2-1. Iodine sorbent test system.

\subsection{Process Gas Supply System}

The process gas supply system consists of pressurized gas cylinders that supply pure air, nitrogen, $\mathrm{NO}_{\mathrm{x}}$, and other gases, iodine and methyl iodide generators, and a humidifier that supplies vaporized water. Air or $\mathrm{N}_{2}$ can be supplied through mass flow controllers separately to the iodine and methyl iodide generators and the humidifier. $\mathrm{NO}$ and $\mathrm{NO}_{2}$ gases, with balance $\mathrm{N}_{2}$, are supplied from compressed gas cylinders through mass flow controllers. The gas flowrates and the generation rates of vaporized iodine, methyl iodide, and water are set to achieve the target blended gas composition and blended in a mixing 
chamber upstream of the sorbent beds. All process lines that contain vaporized iodine, methyl iodide, or water are electrically heat traced.

\subsection{1 lodine Generator}

Three versions of iodine generators have been tested and used in this year or prior years. When low concentrations of iodine, below about $1 \mathrm{ppmv}$ in the blended gas, are desired, then iodine can be generated using a permeation tube system. Permeation tubes contain solid iodine crystals in semipermeable tubes. The tubes emit a known flowrate of iodine at a constant rate which is controlled by the operating temperature of the tube. The tubes (up to two), from VICI Metronics, are placed inside a Dynacalibrator Model 190 constant temperature permeation tube system (shown in Figure 2-2) also from VICI Metronics.

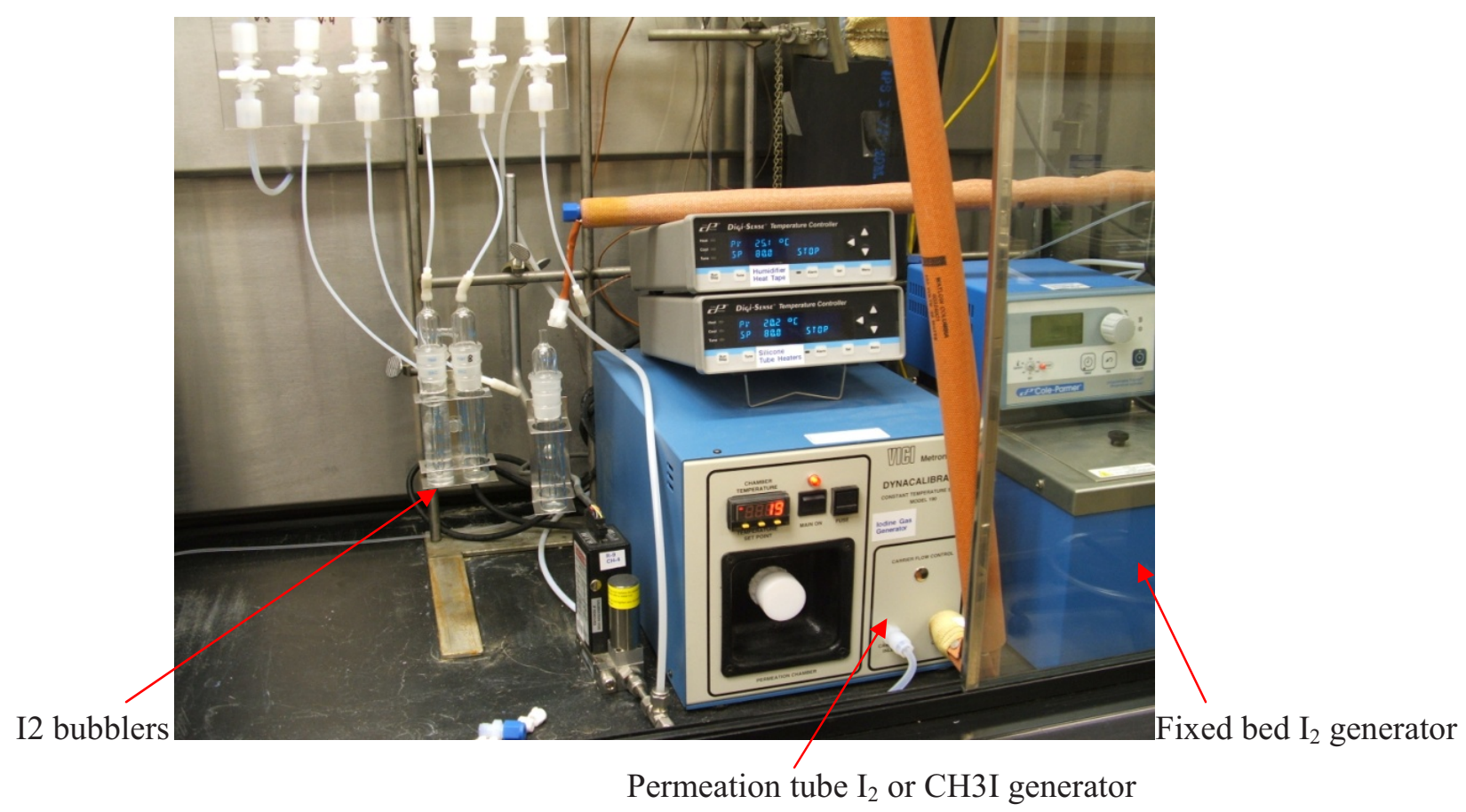

Figure 2-2. View of the iodine bubblers, the permeation tube iodine or methyl iodide generator, and the humidifier.

The VICI Metronics permeation tube system cannot operate at temperatures above $110^{\circ} \mathrm{C}$, the upper limit that the materials of construction can tolerate. The maximum iodine concentration that can be supplied from a maximum of two permeation tubes at this temperature is about $1 \mathrm{ppmv}$ in the blended gas mixtures at a total gas flowrate of about $1.5-2 \mathrm{l} / \mathrm{min}$, the flowrate needed to provide the desired superficial gas velocities in the sorbent beds of at least 10-30 f/s, in the target range of sorbent operating temperatures of about $25-150^{\circ} \mathrm{C}$. For higher iodine flowrates, three types of fixed bed iodine generators were tested, before the third was found to be most acceptable.

The first fixed bed generator that was tried (last year) was a simple fixed bed of iodine in a Teflon chamber, with glass wool in the ends to retain the solid iodine crystals (Figure 2-3). The Teflon chamber was placed inside a temperature-controlled water bath (shown in Figure 2-2 above). Nitrogen or air was passed through the fixed bed. Iodine sublimes at a rate that depends on the temperature of the fixed bed based on the temperature-controlled solid-gas equilibrium. Tests showed that after a time of operation, the duration of which decreased at higher temperatures, the iodine crystals tended to clump together, and 
mass transfer limitations decreased the sublimation rate, making the process less constant. This was not very suitable for providing a constant flowrate and concentration of iodine gas.

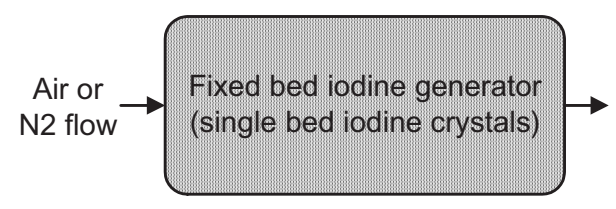

A. Single bed of iodine crystals that tended to clump together and reduce iodine ablation rate.

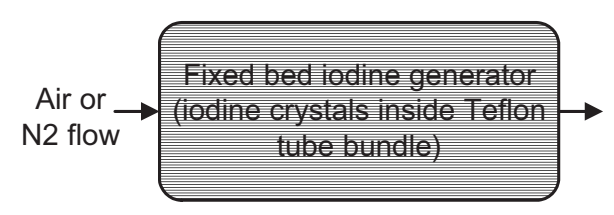

B. Iodine crystals inside a bundle of Teflon tubing; clumping was reduced.

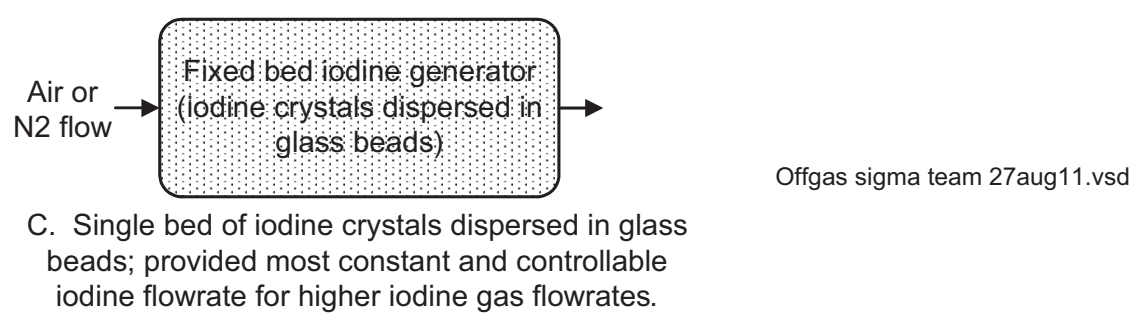

Figure 2-3. First, second, and third generation iodine generators for high iodine flowrates.

A second generation of iodine generator was designed to minimize the degree to which the iodine crystals could clump. A bundle of Teflon tubes was placed inside the Teflon vessel (Figure 2-3 above). Iodine crystals were placed inside the bundle of Teflon tubes. While the iodine crystals inside each tube could clump together over time, the iodine in each tube was separated from the iodine in the other tubes, minimizing the total clumping potential. This was found to deliver a more constant flowrate that decreased less over time compared to the flowrate from the single iodine bed.

A third generation iodine generator was tested and found to be superior to the other two versions. In this version, iodine crystals were mixed with glass beads and placed inside the Teflon vessel (Figure 2-3 above). The iodine crystals, distributed among the glass beads, were generally not in close contact, and so could not clump together. This design, although it still did not provide the maximum flowrate expected if the sublimation process was in thermodynamic solid-gas equilibrium, provided the most constant flowrate. The iodine flowrate and concentration in the blended gas stream was measured periodically whenever the bed outlet iodine concentrations were measured.

\subsubsection{Methyl lodide Generator}

Methyl iodide was also provided two different ways. For low concentrations (under about 1 ppmv in the blended gas), methyl iodide can be provided from a certified compress gas cylinder containing up to about 100 ppm methyl iodide. This was the methyl iodide delivery method used in FY 2010 testing when lower concentrations were used.

For higher methyl iodide concentrations (above about 1 ppmv in the blended gas), it becomes increasingly impractical and costly to use methyl iodide supplied in gas cylinders. In these cases, methyl iodide permeation tubes from VICI Metronics were used in the permeation tube system to provide methyl iodide at concentrations up to about $50 \mathrm{ppmv}$. The higher concentrations of methyl iodide from the permeation tubes were possible (compared to the highest possible iodine concentrations from iodine permeation tubes) because the methyl iodide tubes had higher specific sublimation rates at lower temperatures. 


\subsubsection{Humidifier}

Humidified air was produced by passing air or nitrogen through a fritted glass bubbler submerged in a constant temperature bath. A thermocouple in the headspace of the bubbler provided the temperature of the water-saturated gas. The concentration of water in the blended gas was controlled by adjusting the gas flowrate through the humidifier and the humidifier operating temperature.

\subsection{Sorbent Bed Segments}

Figures 2-4 and 2-5 show detail of the sorbent beds and how the sorbent beds are configured in a temperature-controlled oven.

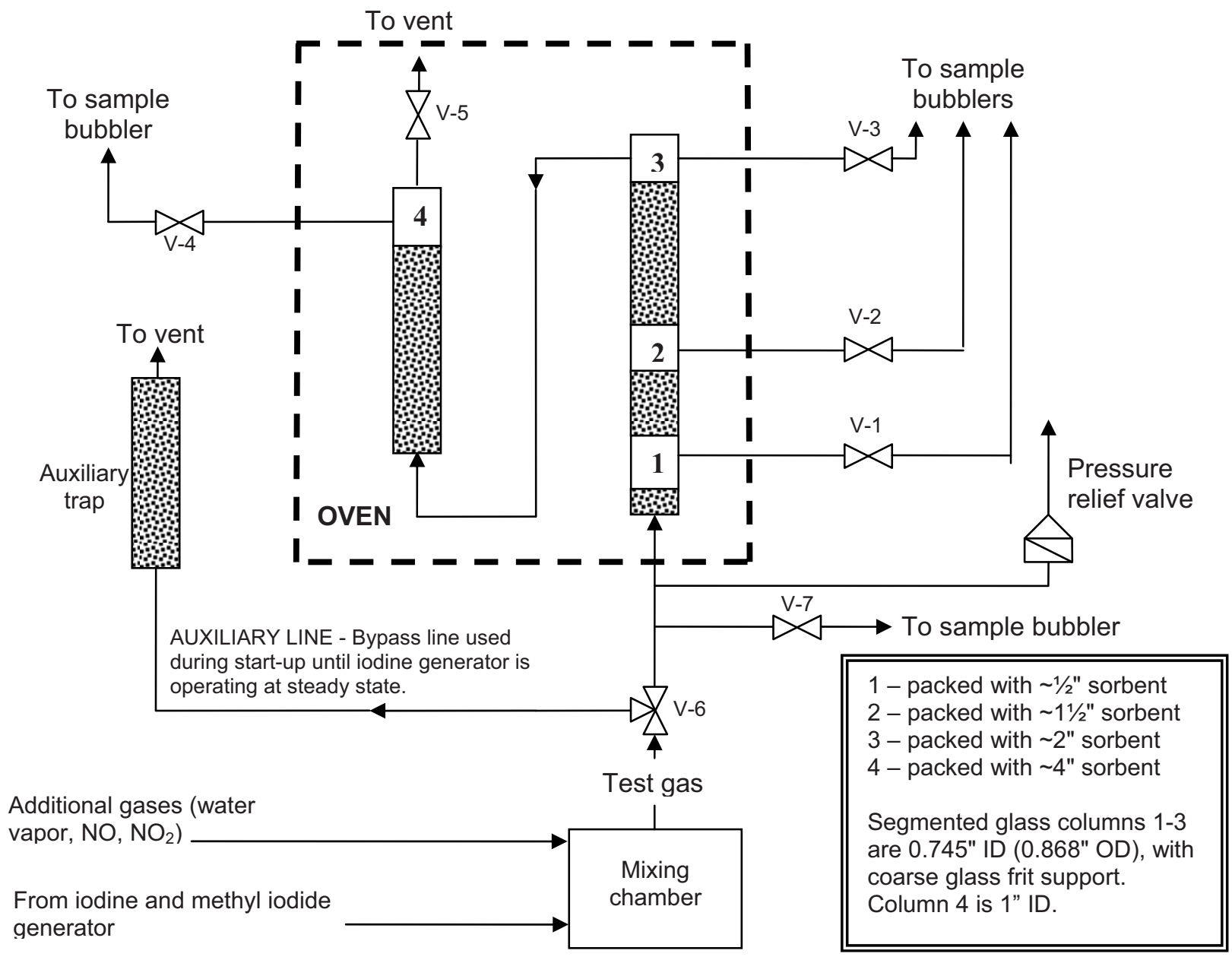

Figure 2-4. Detail of the sorbent beds. At times, only 3 instead of all 4 beds are used. 


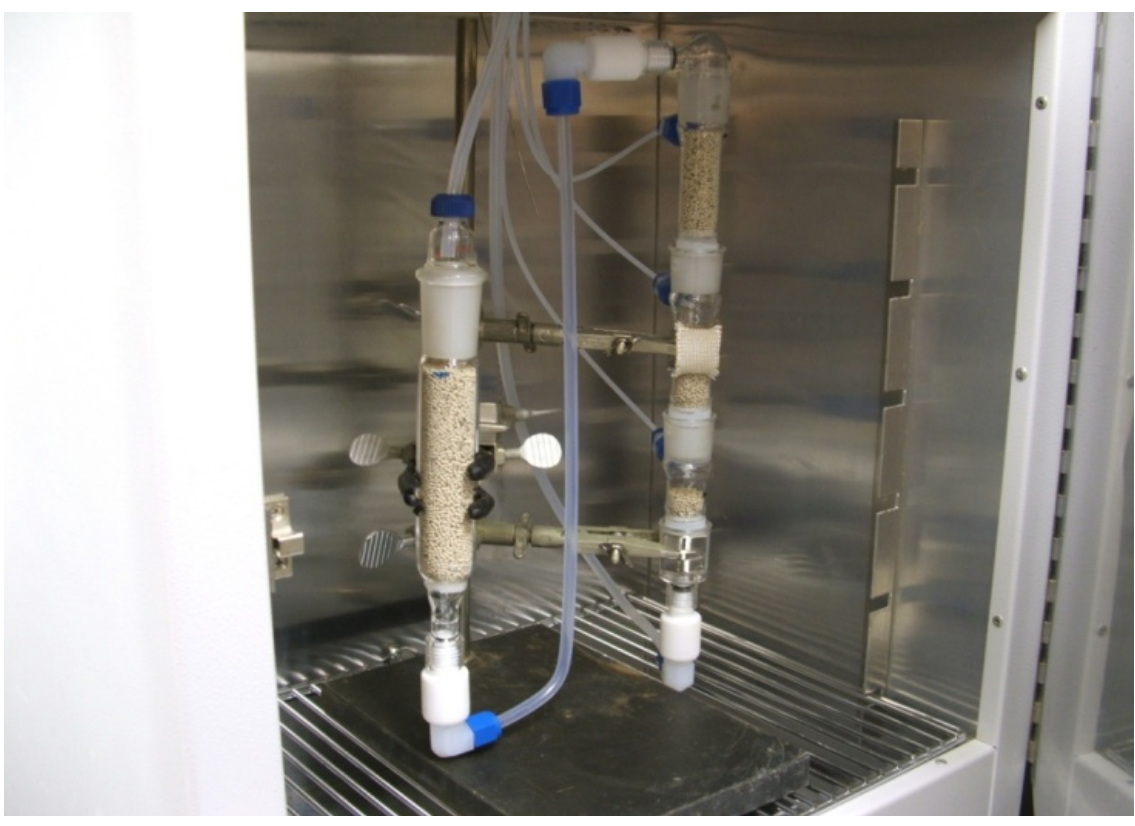

Figure 2-5. Configuration of the sorbent beds inside the temperature-controlled oven.

\subsection{Sample Collection and Analysis}

Iodine and methyl iodide concentrations in the process gas can be measured at up to five locations in the test system (shown in Figure 2-4 above) - at the inlet to the sorbent bed segments, and at the outlet of each of the four bed segments. Since the gas flowrate is essentially the same at all five sample locations, the removal efficiencies for the sorbent in all four beds can be determined by measuring the iodine and methyl iodide concentrations at these locations. By integrating over time and using the process flowrate, the amounts of iodine and methyl iodide sorbed on each of the beds can be calculated.

\subsection{1 lodine Sample Collection and Analysis}

For measuring the gaseous iodine concentration, the process gas from any of the five sample locations is passed through 25-ml "midget" impingers (shown in Figure 2-2 above) that contain $0.1 \mathrm{~N} \mathrm{NaOH}$ for scrubbing halogen gases including $\mathrm{I}_{2}$ and $\mathrm{HI}$, if present. This technique is modeled after EPA Method 26 "Determination of Hydrogen Halide and Halogen Emissions from Stationary Sources, Non-Isokinetic Method" (40 CFR 60 Appendix A). The caustic solution dissolves halogens by hydrolyzing halogen gases to form a proton $\left(\mathrm{H}^{+}\right)$and hypohalous acid. Any HI, if present, dissolves by dissociating in the caustic solution, and is included with $\mathrm{I}_{2}$ in the analysis.

The typical $\mathrm{NaOH}$ concentration in the $25-\mathrm{ml}$ bubblers has been $0.1 \mathrm{~N}$, as specified in Method 26. This provides orders-of-magnitude safety factor in the absorbing capacity of the solution. We occasionally check the $\mathrm{pH}$ of the bubbler solutions to very that the absorbing capability of the solution is not depleted.

The bubbler solutions are analyses by inductively coupled plasma mass spectrometry (ICP-MS) per EPA Method 6020A (SW-846, "Test Methods for Evaluating Solid Wastes Physical/Chemical Methods," http://www.epa.gov/osw/hazard/testmethods/sw846/online/). We can typically detect gaseous iodine concentrations as low as $0.08 \mathrm{ppbv}$ with this method. Higher-concentration samples for gas streams with 1 ppmv or higher iodine concentrations are typically diluted for analysis. 


\subsubsection{Methyl lodide Sampling and Analysis}

Methyl iodide is measured by gas chromatography (GC) following procedures based on EPA Method 18 "Measurement of Gaseous Organic Compound Emissions by Gas Chromatography" (40 CFR 60 Appendix A). The GC used for this measurement is a Hewlett-Packard model 5890 Series II gas chromatograph installed and configured for on-line sampling, thereby allowing near real-time analysis of methyl iodide (Figures 2-6 and 2-7). For sampling, a heated sample line from the GC is manually connected to any of the operator-selected sample locations. The process gas flows through the sample line into a sample loop, and then passed on to the vent. When the operator wants to take a sample he activates the 6-port injector, that rotates so that, simultaneously, the process gas bypasses the sample loop and it vented, and the instantaneous contents of the sample loop (containing a known volume of sample gas) is injected using He carrier gas into the GC column. After the programmed injection time, the injector rotates back so that, simultaneously, the sample gas flows again through the sample loop and then to the vent, and the He carrier gas bypasses the sample loop and continues to flow through the GC column.

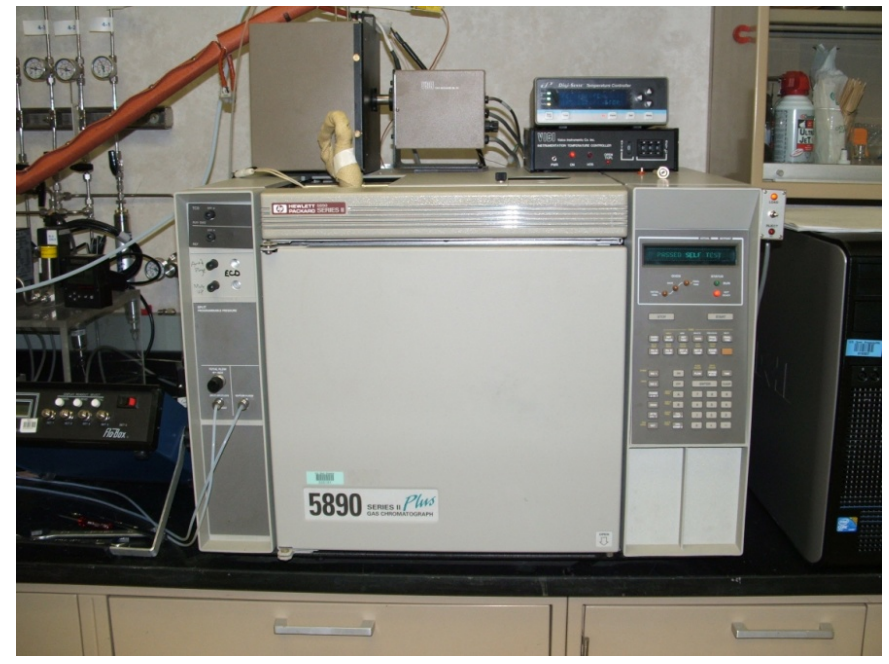

Figure 2-6. On-line GC for methyl iodide analysis. The brown sheathed heated sample enters the heated injector box from the left.

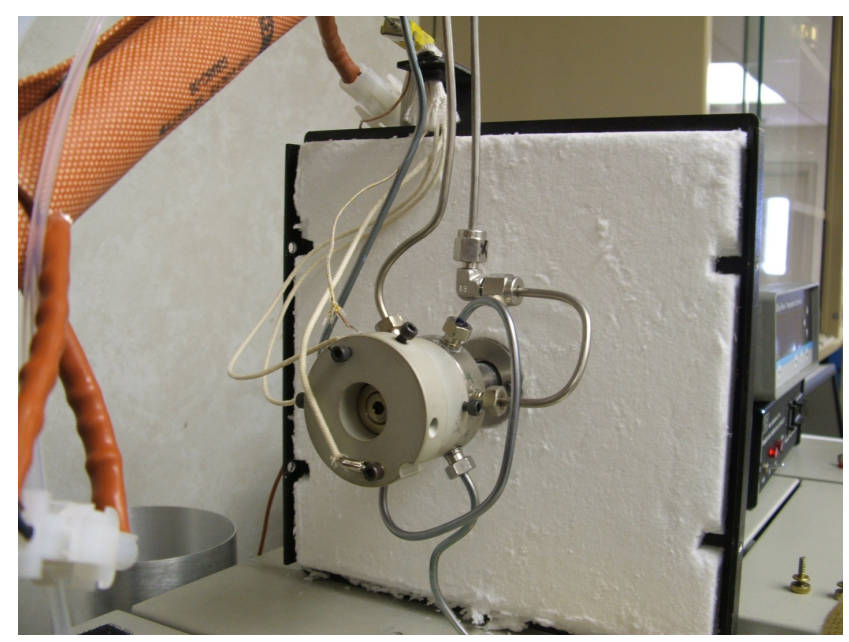

Figure 2-7. The 6-port injector that controls injections of sample gas into the GC. The sample is the stainless steel tubing loop on the right side of the injector. 
The GC is equipped with an HP-Plot Q bonded polystyrene-divinylbenzene (DVB) based column. Its specifications are: $15 \mathrm{~m}$ long $\times 0.320 \mathrm{~mm}$ inside diameter $\times 20 \mathrm{um}$ film. The GC is equipped with an electron capture detector, which is very sensitive to halogenated organic compounds and is well suited for the methyl iodide analysis.

The GC is controlled via a computer that operates the Chemstation Rev. A 10.02 GC controlling software. The GC is calibrated using a 100 ppm methyl iodide certified calibration gas. For lower calibration gas concentrations, this gas is blended down using mass flow controllers that accurately control flowrates of the $100 \mathrm{ppm}$ calibration gas and pure nitrogen into Tedlar bags.

\subsubsection{Sampling and Analysis Lessons Learned}

Some sampling and analysis lessons have been learned this past year and in prior years:

- When control efficiencies in excess of 1,000x are measured, then the iodine species concentrations in the process gas vary by more than $1,000 x$. This means that lab equipment such as bubblers, fittings, and tubing that contacts the higher-concentration gas streams and scrubber solutions can often be contaminated with iodine species at levels that are not easily removed without thorough cleaning. So we have labeled and keep separate impingers and fittings used at each of the 5 potential sample locations. Even with multiple rinsing, if impingers used at the higher-concentration-locations are used in subsequent sample collection at the lowerconcentration-locations, they can result in high-biased results due to contamination.

- The blended gas streams can corrode fittings, tubing, and equipment. The system components must be heated to above dewpoint temperatures to avoid corrosive condensation. System components, in particular for the GC and MS systems, need to be routinely cleaned, maintained, and replaced when necessary.

- Best test results are obtained when sets of samples are collected for analysis at the same time. Each set needs to include the sorbent bed inlet sample and outlet samples from each of the sorbent bed segments. Some variation or drift can occur in the inlet concentrations; obtaining a sample of the inlet gas at the same time the sorbent bed outlet samples are obtained provides tracking of the inlet gas concentrations should they drift over time.

- Sorbent bed breakthrough tests sometimes require 10's or 100's of hours. Sample periods maybe extended to once every 4 hours or more in such cases to minimize sampling and analysis costs.

\subsection{Recommendations for Future Analyses}

As sorbent testing progresses, we have learned that we can improve test results if we can modify or add analysis procedures. These include:

- We tried this year to modify the bubbler method to enable separate scrubbing and analysis of HI (or other acid-soluble iodine species) and $\mathrm{I}_{2}$. We tried this because the FY 2010 test results indicated that the methyl iodide in the process gas may be getting converted to other iodine species (HI is likely) that are not detected by the GC. Following EPA Method 26, we added a bubbler containing $0.1 \mathrm{~N} \mathrm{H}_{2} \mathrm{SO}_{4}$, which is used to adsorb hydrogen halides but does not adsorb the diatomic halogen forms. The results of this test indicated that some of the $\mathrm{I}_{2}$ was still captured in the acid impinger. Future possible refinements, if desired to further try to use this method, include purging pure air or $\mathrm{N}_{2}$ through the impingers to drive any amounts of $\mathrm{I}_{2}$ in the acid impinger (present just due to mass transfer affects) from the acid impinger into the caustic impinger.

- On-line mass spectrometry analysis. The efforts to speciate other iodine species using EPA Method 26 were not initially successful. We have obtained a mass spectrometer designed for on- 
line analyses, and plan to include it in FY 2012 testing. We will evaluate the on-line MS analysis for $\mathrm{I}_{2}, \mathrm{CH}_{3} \mathrm{I}$, and $\mathrm{HI}$ analyses. 


\section{INITIAL TESTING ACTIVITIES AND EQUIPMENT MAINTENANCE}

Initial activities in the fiscal year addressed some questions identified in prior testing:

- We developed at test plan that included activities to address questions from prior testing and to be a guide for additional testing (Soelberg 2010). Additional testing focused on (a) additional sorbents, (b) higher iodine and methyl iodide concentrations (still representative of potential bounding-level aqueous dissolver off-gas streams, and high enough to reduce the expected test time to reach breakthrough), and (c) somewhat higher gas velocities more typical of full-scale operation.

- We updated work control requirements, documentation, and back-up temperature-control to enable extended duration operation that is sometimes needed for testing sorbents long enough to reach breakthrough.

- We performed a study on iodine generator configurations to obtain more stable higherconcentration iodine levels. Results of this study are described in Section 2.1.1. A revised fixedbed iodine generator capable of delivering iodine at concentrations of up to $100 \mathrm{ppm}$ was developed and demonstrated.

- We performed a study of speciating different iodine species, especially $\mathrm{I}_{2}$ and $\mathrm{HI}$, during sample analysis. Initial results were unsuccessful. We plan to evaluate on-line mass spectrometry analysis in future testing to better speciate different iodine species.

- We procured the necessary process gases including a methyl iodide calibration standard and $\mathrm{NO}_{\mathrm{x}}$ gases for the planned tests.

Following sorbent tests 1 and 2 (described in Section 4), we noted questionable GC results during routine calibration checks. We investigated several areas of the GC, considering the potential for equipment corrosion from the relatively corrosive process gas. We eventually replaced many components including tubing, portions of the injector, the column, and the detector. During this GC downtime we performed Test 3 , which was performed without the addition of methyl iodide. (The mass spectrometer system used for off-line iodine analyses has also required periodic cleaning and we expect, in future testing, to continue to periodically check the GC [and other on-line and off-line instrumentation] and perform maintenance necessary to ensure data quality.) 
This page blank 


\section{FY 2011 DEEP BED IODINE SORBENT TEST RESULTS}

Table 1-1 lists three tests that have been performed this fiscal year. Additional tests are still in progress and can be reported in a revision of this report or a future report. Testing was somewhat delayed and limited this year due to initial activities summarized in Section 3 to address some questions of prior testing, and due to a period of maintenance for the on-line GC.

\subsection{Silver Zeolite Sorbent}

Silver zeolite light phase (AgZ-LP) sorbent provided by Oak Ridge National Laboratory (ORNL) was used in the tests reported here. ORNL has also provided "AgZ-natural" sorbent for testing (it has not yet been tested this year). Both were procured from Molecular Products, a company that procures base zeolite material and then ion exchanges or impregnates it with silver. Both of these sorbents were processed at ORNL to reduce the valence state of the impregnated silver to zero valence.

Although Molecular Products produced both of these sorbents, the chemical make-ups and properties were different, as described below:

- $\quad$ "AgZ Natural" uses a base zeolite material identified as AW-300 - a natural zeolite. ORNL reports that this sorbent contains a minimum silver content of 9\%. Sandia National Laboratory reports the make-up as $\left(\mathrm{H}_{0.8} \mathrm{Ca}_{0.25}\right) \mathrm{Al}_{2.75} \mathrm{Si}_{9.61} \mathrm{O}_{24} \mathrm{Ag}_{0.8}$, which is about $10.5 \mathrm{wt} \% \mathrm{Ag}$. The Brunauer, Emmett, and Teller (BET) surface area was estimated at $17.9 \mathrm{~m}^{2} / \mathrm{g}$ (Table 4-2). (Note that the IONEX purchased by the INL and the AgZ natural are very similar materials)

- $\quad$ "AgZ light phase" uses a base zeolite identified as LZM-5, which is a synthetic sodium mordenite (zeolite) manufactured at UOP. The AgZ light phase material was produced by Molecular Products to have a higher silver content than the normally available Ag mordenite sorbent. ORNL indicates the target silver content as $12-15 \%$. Sandia reports the make-up as $\mathrm{H}_{1.4} \mathrm{Al}_{6.76} \mathrm{Si}_{6.58} \mathrm{O}_{24} \mathrm{Ag}_{1.4}$, which is about $16.7 \mathrm{wt} \% \mathrm{Ag}$. The BET surface area is estimated at 62 $\mathrm{m}^{2} / \mathrm{g}$ (Table 4-3).

\subsection{Sorbent Appearance, Calculated Bed Loading, Purge Results}

Fresh AgZ-LP sorbent is shown loaded in the three sorbent bed sections prior to a test in Figure 4-1. Individual pellets of different colors (mainly tan and khaki) are visible. Figure 4-2 shows how the spent sorbent from Test 1 has turned to a pinkish color, apparently from the presence of sorbed iodine. The right-hand beaker contains the Bed 1 sorbent that has been saturated sufficiently that breakthrough occurred. This sorbent contains about $5.0 \mathrm{~g}$ iodine per $100 \mathrm{~g}$ sorbent. The Bed 2 sorbent in the middle beaker has practically the same pink color and contains a calculated $3.1 \mathrm{~g}$ iodine per $100 \mathrm{~g}$ sorbent. Iodine breakthrough occurred in this bed too. The left-hand beaker contains sorbent from Bed 3, which contains very little iodine that was captured after passing through Beds 1 and 2. Only a few pellets, perhaps ones that were at the inlet of this bed, appear to have any pinkish color. 
Table 4-1. First set of iodine sorbent tests performed in FY 2011.

\begin{tabular}{|c|c|c|c|}
\hline Run Number & 1 avg & 2 & 3 \\
\hline Simulate what off-gas? & dissolver & dissolver & dissolver \\
\hline Test dates & End Apr26 & start 2 May 11 & start 21June11 \\
\hline Iodine generator & glass bed & glass bed & glass bed \\
\hline Sorbent & AgZ-LP & AgZ-LP & AgZ-LP \\
\hline wt\% silver & $17 \%$ & $17 \%$ & $17 \%$ \\
\hline Pretest mass, Bed 1, g & 3.49 & 3.48 & 3.45 \\
\hline Pretest mass, Bed 2, g & 10.16 & 10.4 & 9.97 \\
\hline Pretest mass, Bed 3, g & 13.06 & 13.03 & 12.97 \\
\hline Pretest mass, Bed 4, g & 0 & 0 & 0 \\
\hline Pretest total mass, Total, $g$ & 26.71 & 26.91 & 26.39 \\
\hline Post-test mass, Bed 1, g & 3.48 & 3.44 & 3.61 \\
\hline Post-test mass, Bed 2, g & 10.4 & 10.08 & 10.28 \\
\hline Post-test mass, Bed 3, g & 13.03 & 13.2 & 13.75 \\
\hline Post-test mass, Bed 4, g & 0 & 0 & 0 \\
\hline Post-test total mass, Total, $\mathrm{g}$ & 26.91 & 26.72 & 27.64 \\
\hline delta mass, Bed 1, g & -0.01 & -0.04 & 0.16 \\
\hline delta mass, Bed 2, $\mathrm{g}$ & 0.24 & -0.32 & 0.31 \\
\hline delta mass, Bed 3, g & -0.03 & 0.17 & 0.78 \\
\hline delta mass, Bed 4, $g$ & 0 & 0 & 0 \\
\hline delta mass, total, $\mathrm{g}$ & 0.2 & -0.19 & 1.25 \\
\hline \multicolumn{4}{|l|}{ I2 fixed bed system } \\
\hline Barometric pressure, in. $\mathrm{Hg}$ & 25.5 & 25.5 & 25.5 \\
\hline Water bath $\mathrm{T}$, deg. $\mathrm{C}$ & 25 & 45 & 36 \\
\hline Carrier gas type & $\mathrm{N} 2$ & $\mathrm{~N} 2$ & $\mathrm{~N} 2$ \\
\hline Carrier gas rate, $\mathrm{sccm}$ & 10 & 10 & 230 \\
\hline I2 conc., ppm & 520 & 841 & 433 \\
\hline$\%$ of I 2 saturation level & 1 & 0.35 & 0.35 \\
\hline \multicolumn{4}{|l|}{ CH3I Permeation tube system } \\
\hline Permeation oven $\mathrm{T}$, deg. $\mathrm{C}$ & 55 & 78 & 40 \\
\hline Tube 1 type $(\mathrm{CH} 3 \mathrm{I})$ & $\mathrm{CH} 3 \mathrm{I}$ & $\mathrm{CH} 3 \mathrm{I}$ & $\mathrm{CH} 3 \mathrm{I}$ \\
\hline Tube 1 std permeation rate, $\mathrm{ng} / \mathrm{min}$ & 20,269 & 20,269 & 0 \\
\hline Tube 1 certification $\mathrm{T}$, deg. $\mathrm{C}$ & 50 & 50 & 50 \\
\hline Tube 1 actual permeation rate, $\mathrm{ng} / \mathrm{min}$ & 28,631 & 140,227 & 0 \\
\hline Tube 2 type $(\mathrm{CH} 3 \mathrm{I})$ & CH3I & CH3I & CH3I \\
\hline Tube 2 permeation rate, $\mathrm{ng} / \mathrm{min}$ & 18,798 & 18,798 & 18,798 \\
\hline Tube 2 certification T, deg. $\mathrm{C}$ & 50 & 50 & 50 \\
\hline Tube 2 actual permeation rate, $\mathrm{ng} / \mathrm{min}$ & 26,553 & 130,050 & 9,421 \\
\hline Carrier gas type & N2 & N2 & $\mathrm{N} 2$ \\
\hline Carrier gas rate, $\mathrm{sccm}$ & 200 & 800 & 565 \\
\hline T arget $\mathrm{CH} 3 \mathrm{I}$ conc in carrier gas, ppmv & 26.2 & 32.1 & 0 \\
\hline \multicolumn{4}{|l|}{ Humidifier system } \\
\hline Humidifer oven $\mathrm{T}$, deg. $\mathrm{C}$ & 24.3 & 31 & 30 \\
\hline Humidifier oven $\mathrm{P}$, inches $\mathrm{Hg}$ & 25.5 & 25.5 & 25.5 \\
\hline Humidifier saturation efficiency, $\%$ & 0.95 & 0.95 & 0.95 \\
\hline Carrier gas type & N2 & $\mathrm{N} 2$ & N2 \\
\hline Carrier gas rate, $\mathrm{sccm}$ & 779 & 465 & 480 \\
\hline Carrier gas moisture content, vol $\% \mathrm{H} 2 \mathrm{O}$ & 3.41 & 4.85 & 4.58 \\
\hline Total gas flowrate & 804 & 489 & 503 \\
\hline \multicolumn{4}{|l|}{ Other gases } \\
\hline NO ppmv & 5,666 & 10,000 & 10,000 \\
\hline NO2 ppmv & 6,667 & 10,000 & 10,000 \\
\hline $\mathrm{NO}$ gas rate, sccm & 329 & 123 & 123 \\
\hline $\mathrm{NO} 2$ gas rate, sccm & 204 & 123 & 123 \\
\hline
\end{tabular}


Table 4-1 (continued). First set of iodine sorbent tests performed in FY 2011.

\begin{tabular}{|c|c|c|c|}
\hline Run Number & $1 \mathrm{avg}$ & 2 & 3 \\
\hline Simulate what off-gas? & dissolver & dissolver & dissolver \\
\hline Test dates & End Apr26 & start 2 May 11 & start 21 June11 \\
\hline Iodine generator & glass bed & glass bed & glass bed \\
\hline \multicolumn{4}{|l|}{ Sorption conditions } \\
\hline Oven $\mathrm{T}$, deg. $\mathrm{C}$ & 150 & 150 & 150 \\
\hline Total gas flowrate, sccm & 1,547 & 1,544 & 1,543 \\
\hline Average gas mole weight & 27.8 & 27.8 & 27.9 \\
\hline Target $I 2$ conc, ppmv & 3.4 & 5.4 & 64.5 \\
\hline Me asured $I 2$ conc, ppmv & 4.5 & 5.6 & 80.4 \\
\hline Target $\mathrm{CH}$ I I conc, ppmv & 3.4 & 16.6 & 0 \\
\hline Measured CH3I conc, ppmv & 6.1 & 17.1 & 0 \\
\hline Target total I flowrate, $\mathrm{mg} / \mathrm{min}$ & 0.08 & 0.22 & 1.05 \\
\hline Time for iodine mass $1 \%$ Bed $1, \mathrm{hr}$ & 7.1 & 2.6 & 0.5 \\
\hline Me asured total I flowrate, $\mathrm{mg} / \mathrm{min}$ & 0.12 & 0.23 & 1.31 \\
\hline Measured dP all beds, in. $\mathrm{H} 2 \mathrm{O}$ & 3.9 & 2.0 & 3.4 \\
\hline H2O conc, $\%$ & 1.61 & 1.54 & 1.49 \\
\hline $\mathrm{H} 2 \mathrm{O}$ dewpoint, deg. $\mathrm{C}$ & 11.5 & 10.9 & 10.5 \\
\hline NO conc, ppmv & 795 & 794 & 794 \\
\hline NO2 conc, ppmv & 792 & 794 & 794 \\
\hline Balance & $\mathrm{N} 2$ & $\mathrm{~N} 2$ & $\mathrm{~N} 2$ \\
\hline Sorption gas velocity, f/min & 30.1 & 30.0 & 30.0 \\
\hline Bed 1 out residence $t$, sec & 0.08 & 0.08 & 0.08 \\
\hline Bed 2 out cumulative residence $t$, sec & 0.33 & 0.33 & 0.33 \\
\hline Bed 3 out cumulative residence $t$, sec & 0.66 & 0.67 & 0.67 \\
\hline Bed 4 out cumulative residence $t$, sec & --- & --- & --- \\
\hline Cumulative test duration, hr & 129 & 45 & 39 \\
\hline Final iodine loading on Bed 1, wt $\%$ & $5.0 \%$ & $3.5 \%$ & $40.1 \%$ \\
\hline Final iodine loading on Bed 2, wt $\%$ & $3.1 \%$ & $2.8 \%$ & $7.1 \%$ \\
\hline Final silver utilization, mole \%, Bed 1 & $24.9 \%$ & $17.9 \%$ & $204.1 \%$ \\
\hline Final silver utilization, mole $\%$, Bed 2 & $15.6 \%$ & $14.1 \%$ & $36.0 \%$ \\
\hline Minimim (initial) Bed 1 out iodine conc, ppmv & 0.0088 & 1.6 & 32 \\
\hline Minimum initial Bed 2 out iodine conc, ppmv & 0.0039 & 0.0097 & 0.26 \\
\hline Minimum (initial) Bed 3 out iodine conc, ppmv & 0.0055 & 0.0012 & 0.0021 \\
\hline Minimum (initial) Bed 4 out iodine conc, ppmv & --- & --- & --- \\
\hline Maximum (initial) Bed 1 out iodine DF & 510 & 4 & 3 \\
\hline Maximum (initial) Bed 2 out cum iodine DF & 1,206 & 1,892 & 314 \\
\hline Maximum (initial) Bed 3 out cum iodine DF & 8,800 & 6,442 & 54,677 \\
\hline Maximum (initial) Bed 4 out cum iodine DF & --- & --- & --- \\
\hline Minimum (initial) Bed 1 out $\mathrm{CH} 3 \mathrm{I}$ conc, ppmv & 0.0154 & 1.80 & --- \\
\hline Minimum (initial) Bed 2 out $\mathrm{CH} 3 \mathrm{I}$ conc, ppmv & 0.0034 & 0.20 & --- \\
\hline Minimum (initial) Bed 3 out $\mathrm{CH} 3 \mathrm{I}$ conc, ppmv & 0.0029 & 0.21 & --- \\
\hline Minimum (initial) Bed 4 out CH3I conc, ppmv & --- & --- & --- \\
\hline Maximum (initial) Bed 1 out CH3I DF & 397 & 9 & --- \\
\hline Maximum (initial) Bed 2 out cum CH3I DF & 3,706 & 99 & --- \\
\hline Maximum (initial) Bed 3 out cum CH3I DF & 14,723 & 115 & --- \\
\hline Maximum (initial) Bed 4 out cum CH3I DF & --- & --- & --- \\
\hline
\end{tabular}


Table 4-2. Surface area measurements for the AgZ natural sorbent.

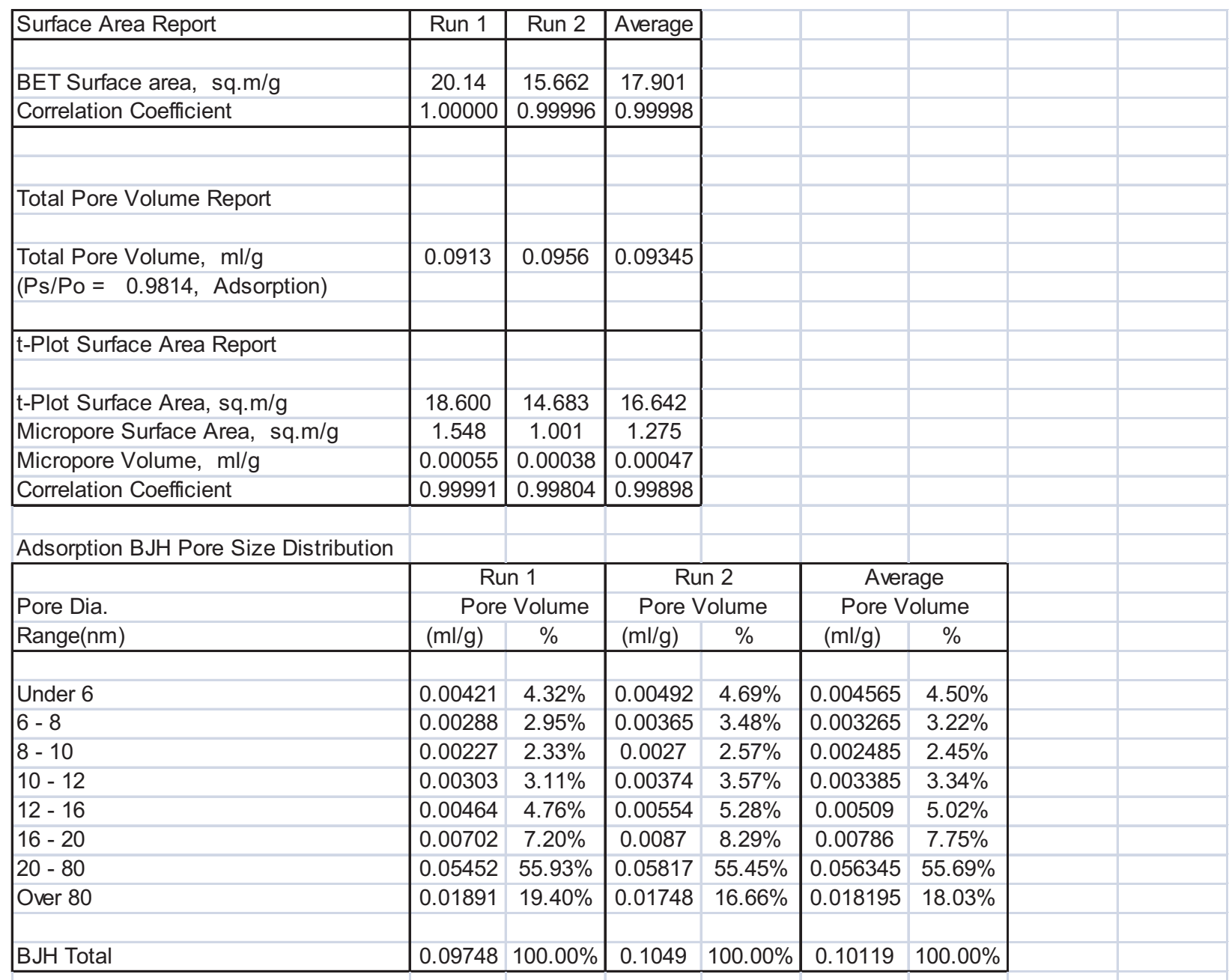

Isotherm

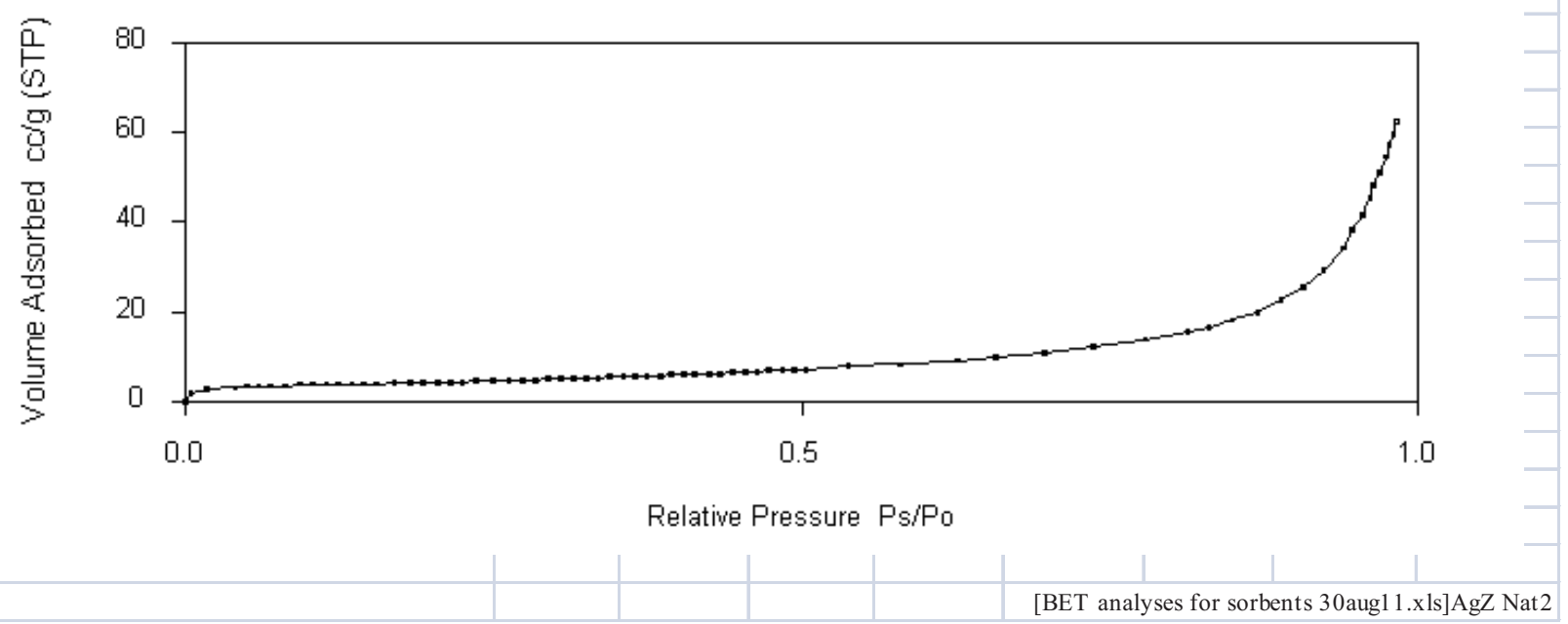


Table 4-3. Surface area measurements for the AgZ light phase sorbent.

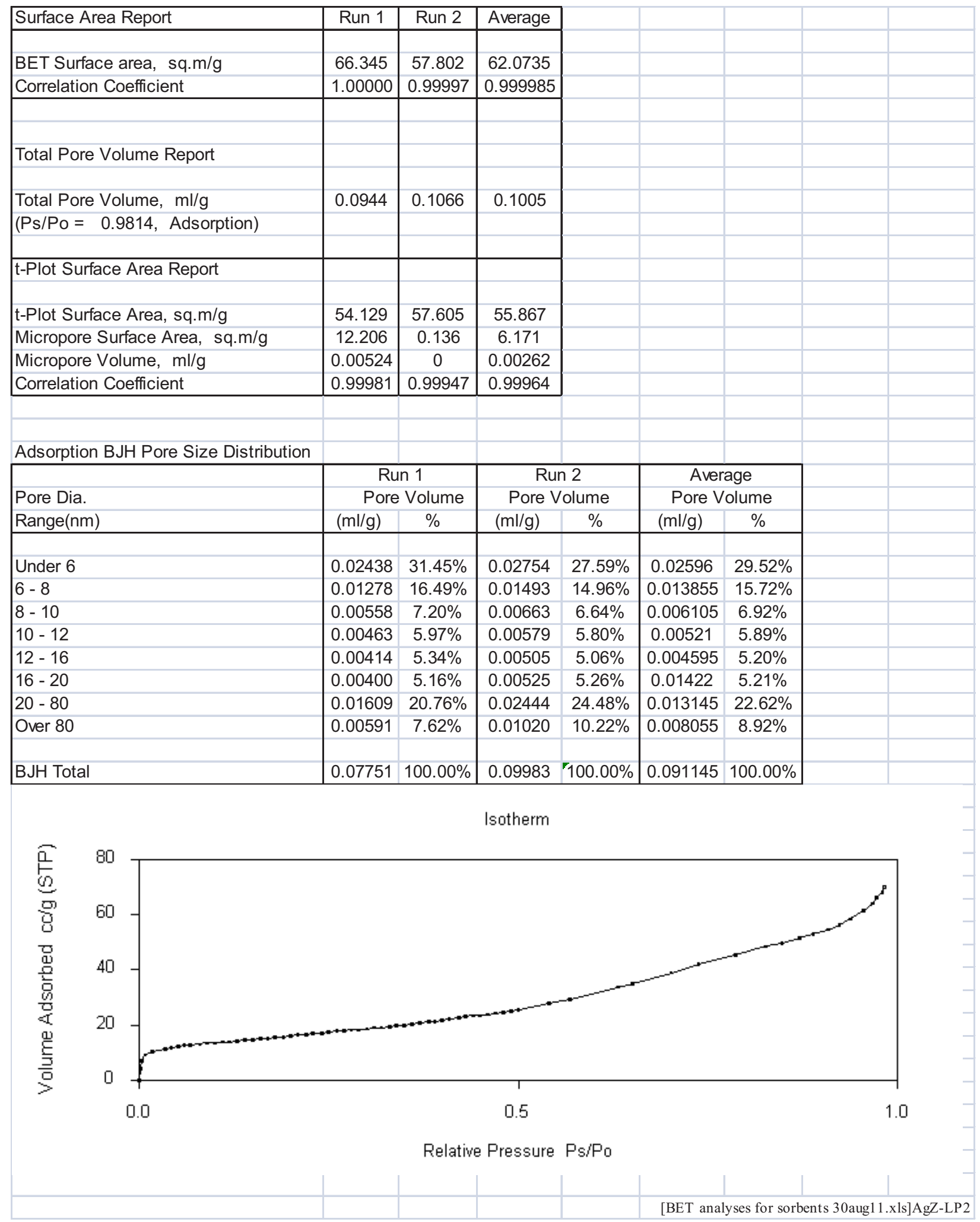




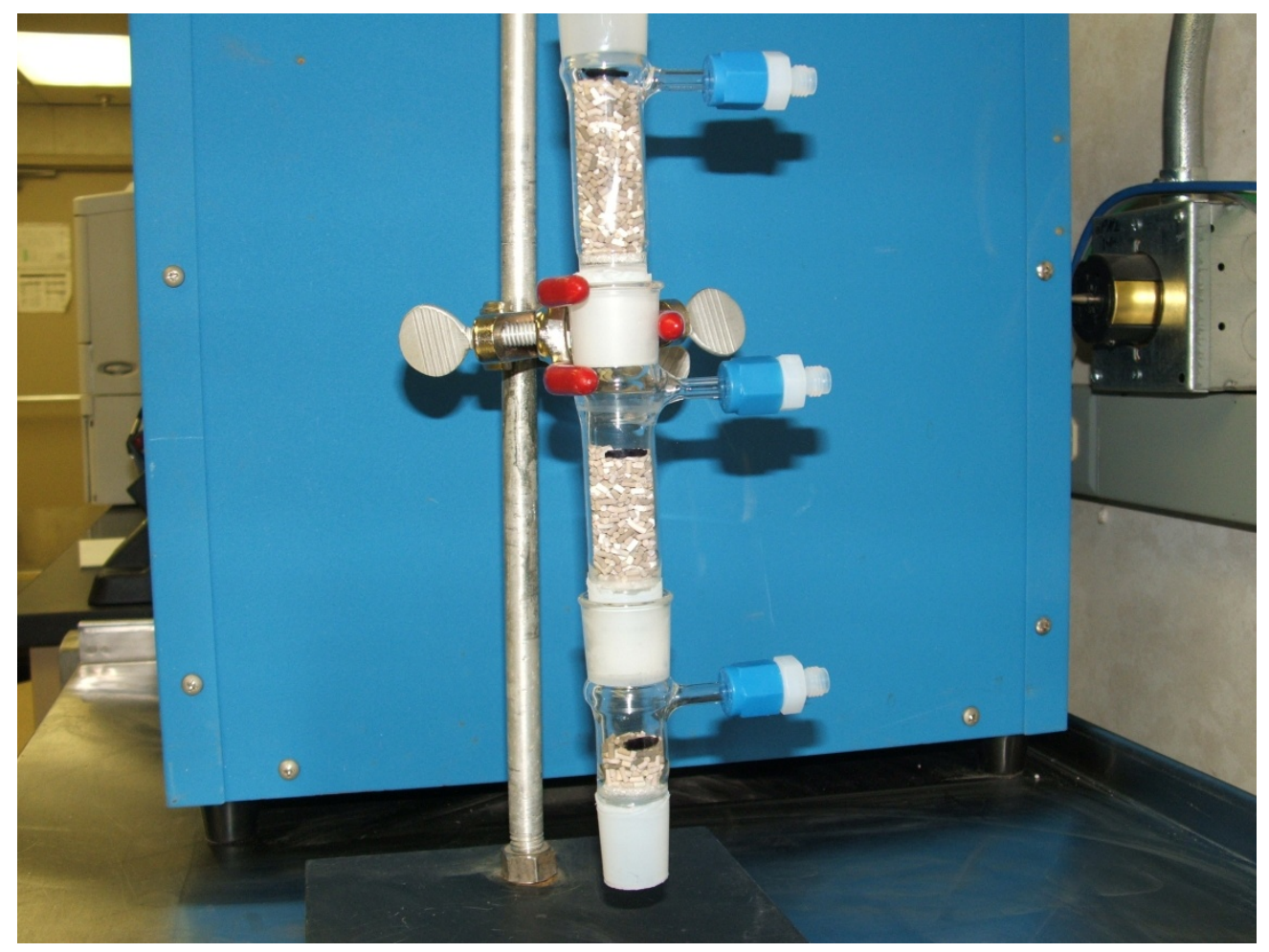

Figure 4-1. Fresh AgZ-LP sorbent loaded into the 3 sorbent bed segments.

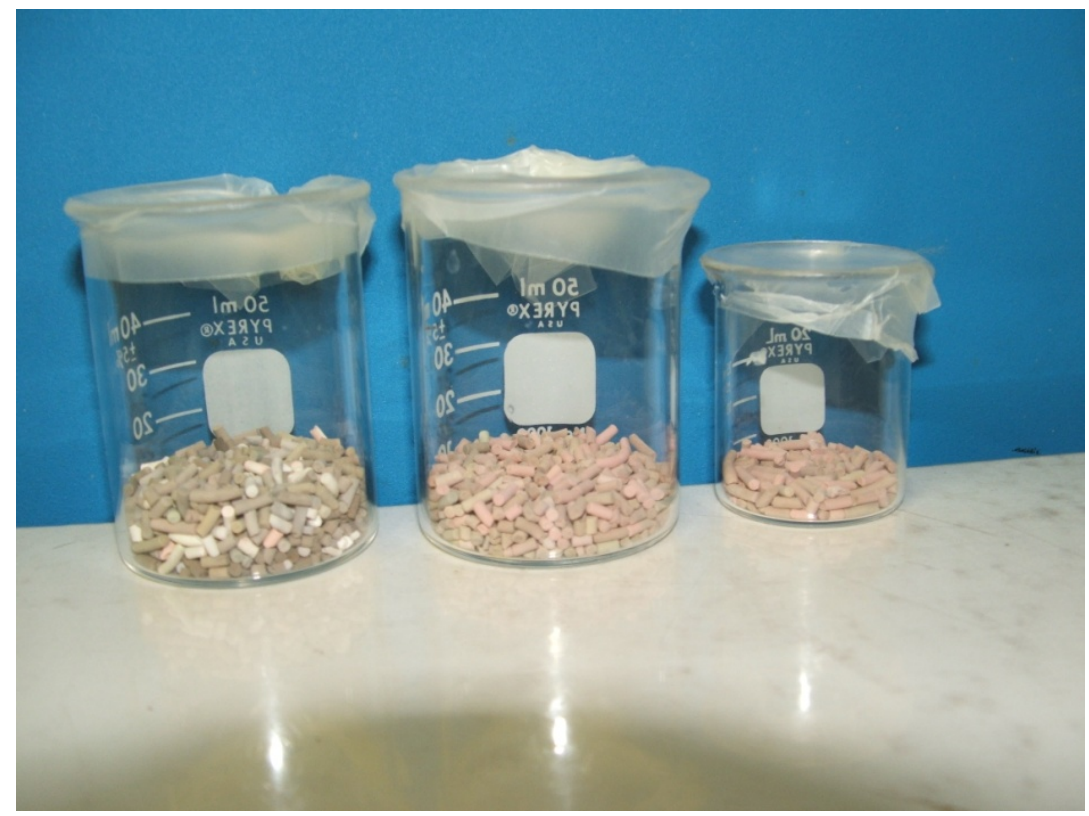

Figure 4-2. Spent AgZ-LP sorbent after Test 2. 
The sorbent loadings were calculated using the inlet and outlet off-gas measurements and the test duration. However, after each test, the sorbent beds are purged with pure $\mathrm{N}_{2}$ to desorb any amounts of iodine or methyl iodide that may be loosely or physisorbed. The purge results are recorded but are not included here in detail. The Bed 1 outlet $\mathrm{I}_{2}$ concentrations during bed purging after Test 1 (after the Test 1 inlet $\mathrm{I}_{2}$ and $\mathrm{CH}_{3} \mathrm{I}$ concentrations ranged between about 2-5 ppm) ranged as high as $0.8 \mathrm{ppm}$; Bed 2 outlet $\mathrm{I}_{2}$ concentrations ranged below $0.5 \mathrm{ppm}$; and Bed 3 outlet $\mathrm{I}_{2}$ concentrations were very low, ranging around $10 \mathrm{ppb}$. Even though there appeared to be some evolution of iodine from Bed 1 into Bed 2 and from Bed 2 into Bed 3, desorption from Bed 3 during purging was negligible. More detailed analyses can be done to calculate what portion of the sorbed iodine migrated from Bed 1 into Bed 2 and from Bed 2 into Bed 3.

The sorbent loadings from Test 3, at $40.1 \%$ in Bed 1, and a whopping $200+\%$ calculated silver utilization) are much higher than for the other two tests. This is because of the much higher inlet iodine concentration, which averaged about $100 \mathrm{ppm}$ for most of the test duration.

Levels of methyl iodide in the bed outlet gas streams during purging were measureable but essentially at the method detection limits. So either the sorbent has efficiently retained any sorbed methyl iodide, or (as suggested in the FY 2010 iodine test report (Haefner 2010) the methyl iodide could have been reacted to form other compounds not detected in the GC analysis and not speciated or captured in the iodine bubbler analysis.

The post-test purge results for Tests 2 and 3 are similar to those of Test 1:

- Measureable iodine emissions were detectable but at lower levels than were in the inlet gas during the test, and tended to decrease over time

- Some iodine appears to migrate from Bed 1 to Bed 2 and into Bed 3, but when Bed 3 has not reached breakthrough, then the iodine desorbed from Bed 2 is captured efficiently in Bed 3. This is a likely trend that would occur in a full-scale process - as long as the full depth of a sorbent bed is not saturated, the remaining unsaturated sorbent can serve as a "getter" for physisorbed iodine that may slowly desorb from saturated sorbent pellets. The end result might possibly be efficient retention of the physisorbed iodine as it migrates from physisorption sites into sites were the iodine can chemisorb via reaction with the silver.

Portions of the Bed 1 samples from tests 1 and 2 have been shipped to SNL for waste form studies.

\subsection{Test 1 lodine and Methyl lodide Sorption Results}

Process gas was sampled periodically during the duration of each test to enable determination of bed inlet and outlet iodine and methyl iodide concentrations and sorption efficiencies. Figure 4-3 shows how the inlet iodine concentration and the bed sorption efficiencies (reported as decontamination factors, DFs) trended for the duration of Test 1. 


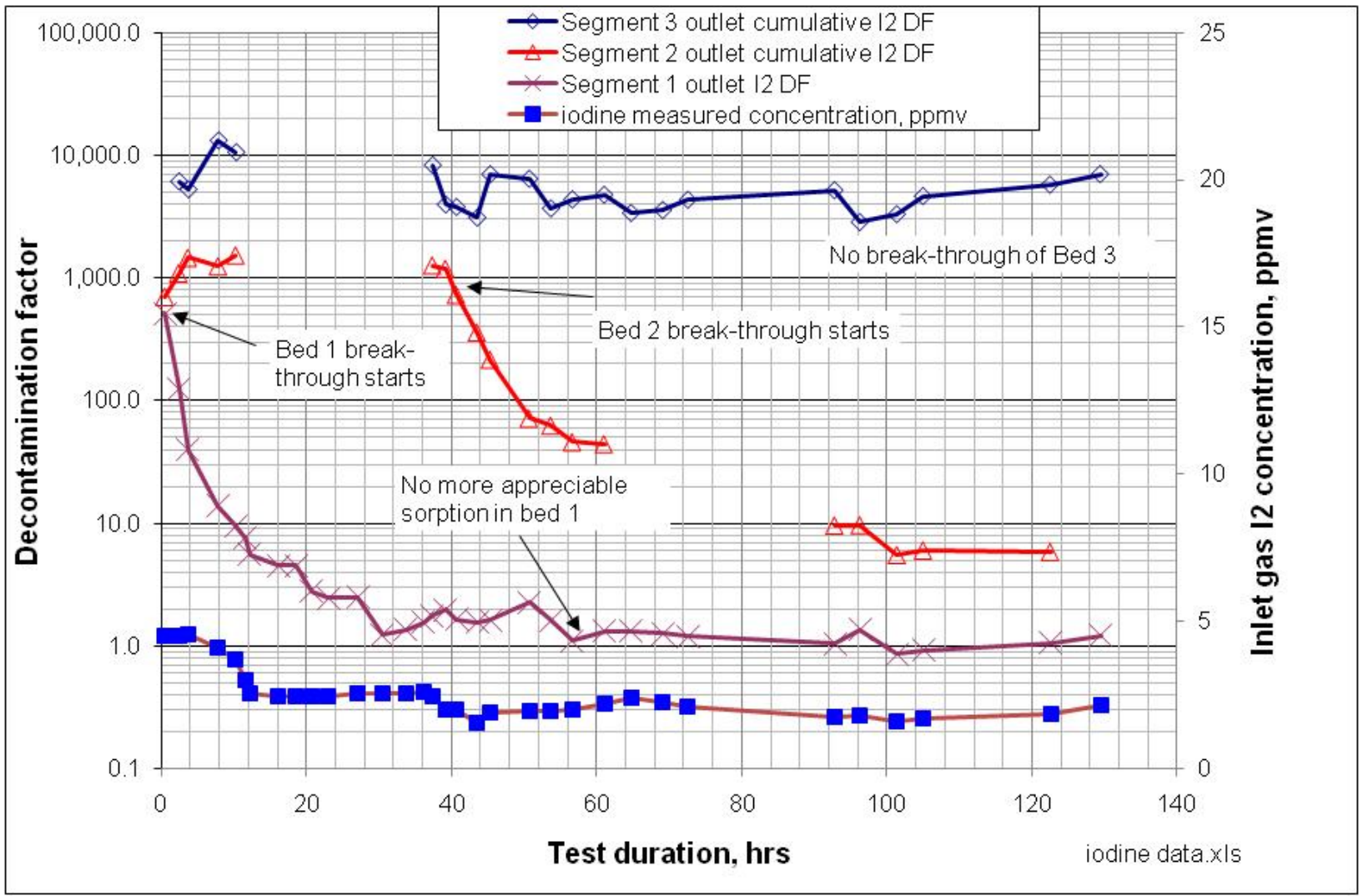

Figure 4-3. Test 1AgZ-LP iodine sorption results.

\subsubsection{Test 1 lodine Sorption Results}

This test provided the following results:

- The inlet iodine concentration ranged between 2-3 ppm for most of the test duration.

- Maximum DFs prior to breakthrough ranged between 1,000-10,000, high enough to provide the expected necessary iodine control efficiency in an operating separations plant.

- Bed 1 broke through nearly immediately, but did not reach full saturation (when the DF decreased to about 1) until about hour 60 in the $129 \mathrm{hr}$ test duration.

- Bed 2 breakthrough began by about hour 40 .

- The near-immediate breakthrough of Bed 1shows that the mass transfer zone (MTZ) for the test conditions was at least 0.5 inches deep (the depth of Bed 1). The delayed breakthrough of Bed 2 shows that the mass transfer zone (MTZ) for the test conditions is less than 2 inches (the combined depth of Beds 1 and 2). A more detailed analysis could be done to estimate a more specific MTZ depth, but it would require assuming a slope of the iodine concentration in the MTZ. The slope of the sorbate concentration in the sorbent (indicated in Figure 4-4) could be steep or shallow. The long duration of time needed to reach a $D F=1$ in the Bed 1 shows that the MTZ is at least 1.5 inches long - because the front of the MTZ reached the 2-inch depth in about 40 hours, and the tail end of MTZ did not exit the 0.5-inch-deep Bed 1 until after 60 hours. Without further analyses, the depth of the MTZ under the conditions of Test 1 is between 1.5-2 inches. 
- The 2-inch-deep Bed 3 did not break through. The total 3-bed sorbent depth of 4 inches maintained relatively constant DF of 3,000-7,000 for most of the time.

- Bed $1 \mathrm{Ag}$ utilization reached $25 \mathrm{wt} \%$; under the test conditions much of the silver appears to be unutilized when the Bed 1 DF approached essentially zero; however, over time during or after operation, it could be likely that as-yet-unchemisorbed iodine might continue to migrate and react with available silver.

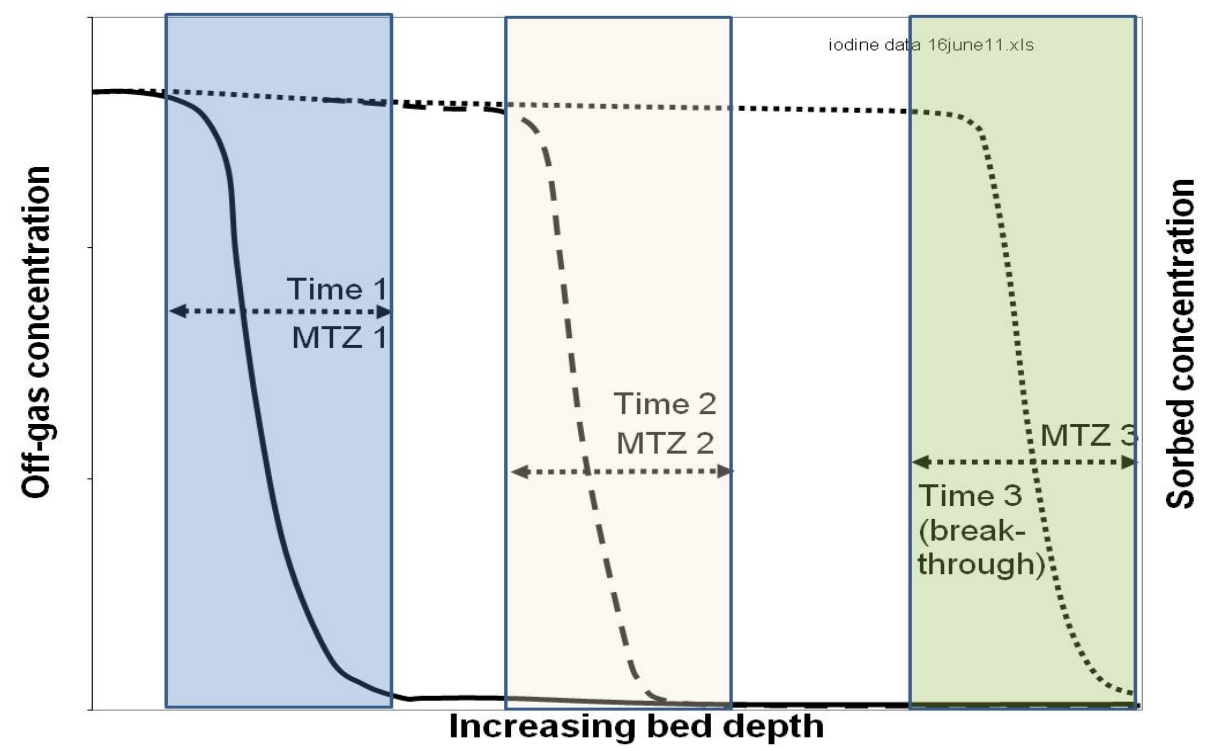

Figure 4-4. Mass transfer zone, the zone in the sorbent bed were sorption occurs the most and gas-phase and sorbent-phase concentrations of the sorbate are rapidly changing.

\subsubsection{Test 1 Methyl lodide Sorption Results}

Figure 4-5 shows how the inlet methyl iodide concentration and the bed sorption efficiencies (reported DFs) trended for the duration of Test 1. Summary results include:

- The measured inlet methyl iodide levels ranged between about 2-5 ppm for most of the test duration.

- As in the FY 2010 test results, there could have been some reaction of methyl iodide to form species that were not detectable using the GC and that were not speciated or captured in the iodine bubbler analysis. We suspect this because, even after 129 operating hours, there is no clearly detectable breakthrough of methyl iodide from even Bed 1.

- The Bed 1 DFs ranged relatively constant between about 200-400, lower than DFs for Beds 2 and 3 , which ranged between about 500-1,000 for most of the test duration (peaking over 30,000 at the test start). 


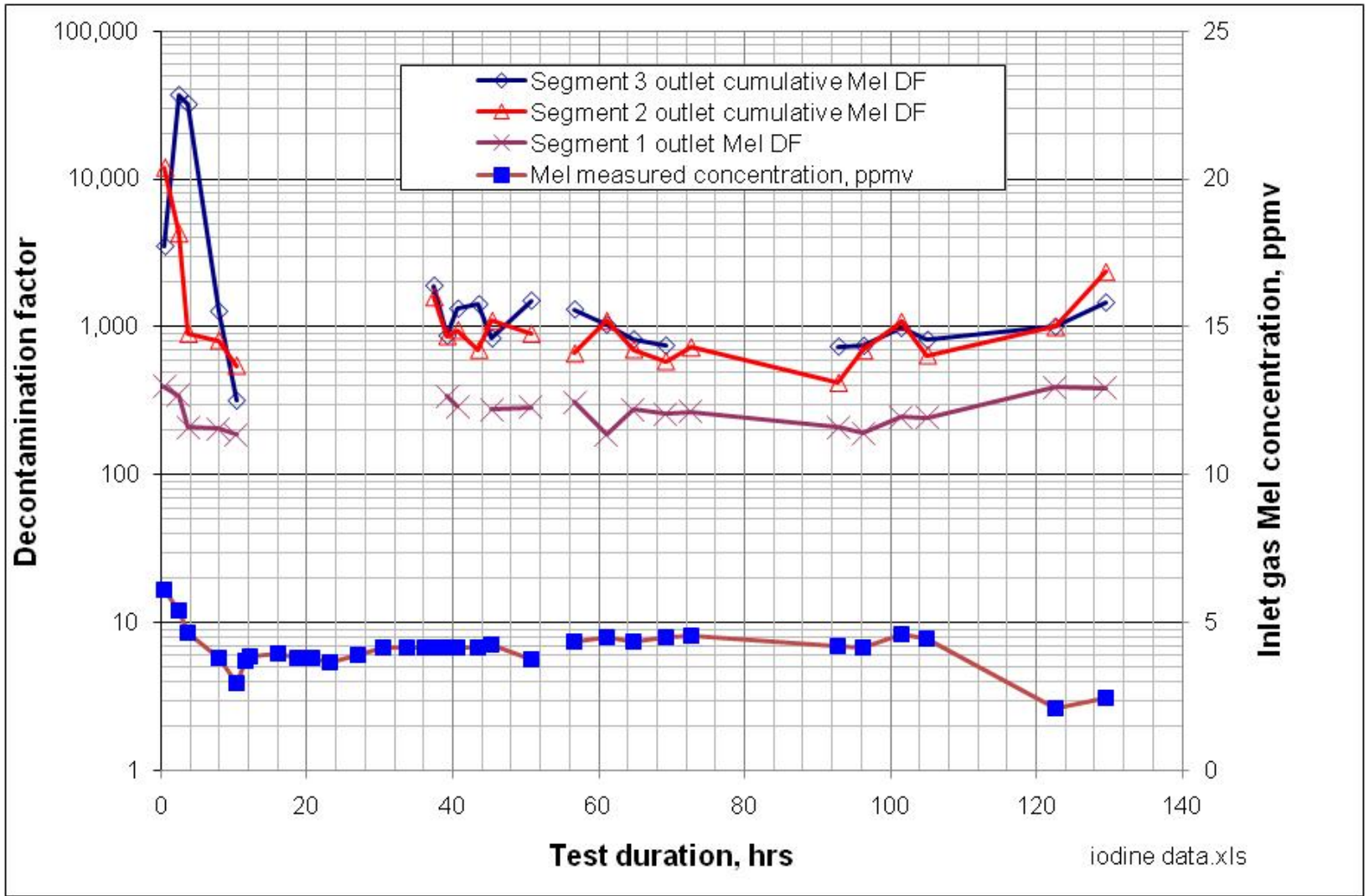

Figure 4-5. Test 1AgZ-LP methyl iodide sorption results.

\subsection{Test 2 lodine and Methyl lodide Sorption Results}

Figure 4-6 shows how the inlet iodine concentration and the bed sorption efficiencies (reported as decontamination factors, DFs) trended for the duration of Test 2. For Test 2, the inlet iodine concentrations were slightly higher, and the inlet methyl iodide concentrations were about 4 times higher.

\subsubsection{Test 2 lodine Sorption Results}

This test provided the following results:

- The inlet iodine concentration ranged between 3-5 ppm for most of the test duration.

- Maximum DFs prior to breakthrough ranged between 2,000-10,000, high enough to provide the expected necessary iodine control efficiency in an operating separations plant.

- Bed 1 broke through nearly immediately (sooner than the first sample period, which was about 4 hours after the test start) but did not reach full saturation (when the DF decreased to about 1) until about hour 15 hours in the $45 \mathrm{hr}$ test duration.

- $\quad$ Bed 2 breakthrough began by about hour 9 .

- The near-immediate breakthrough of Bed 1shows that the MTZ for the test conditions was at least 0.5 inches deep (the depth of Bed 1). The delayed breakthrough of Bed 2 shows that the MTZ for the test conditions is less than 2 inches (the combined depth of Beds 1 and 2). The long duration of time needed to reach a DF=1 in the Bed 1 shows that the MTZ is at least 1.5 inches long because the front of the MTZ reached the 2-inch depth in about 9 hours, and the tail end of MTZ 
did not exit the 0.5 -inch-deep Bed 1 until after 15 hours. Without further analyses, the depth of the MTZ under the conditions of Test 1 is between 1.5-2 inches.

- The 2-inch-deep Bed 3 did not break through. The total 3-bed sorbent depth of 4 inches maintained relatively constant DF of 3,000-10,000 for most of the time.

- Bed 1 Ag utilization only approached $18 \mathrm{wt} \%$; under the test conditions even more silver remained unutilized than in Test 1 . This may be due to the shorter test time for Test 2 . The test time was shortened because of the higher total iodine + methyl iodide input rate. Perhaps under the test conditions, the presence of the higher methyl iodide levels interfered with the sorption of the iodine, since the iodine DF for bed 1 dropped to 1 , and even when the total iodine loading and the Ag utilization was less than for Test 1 .

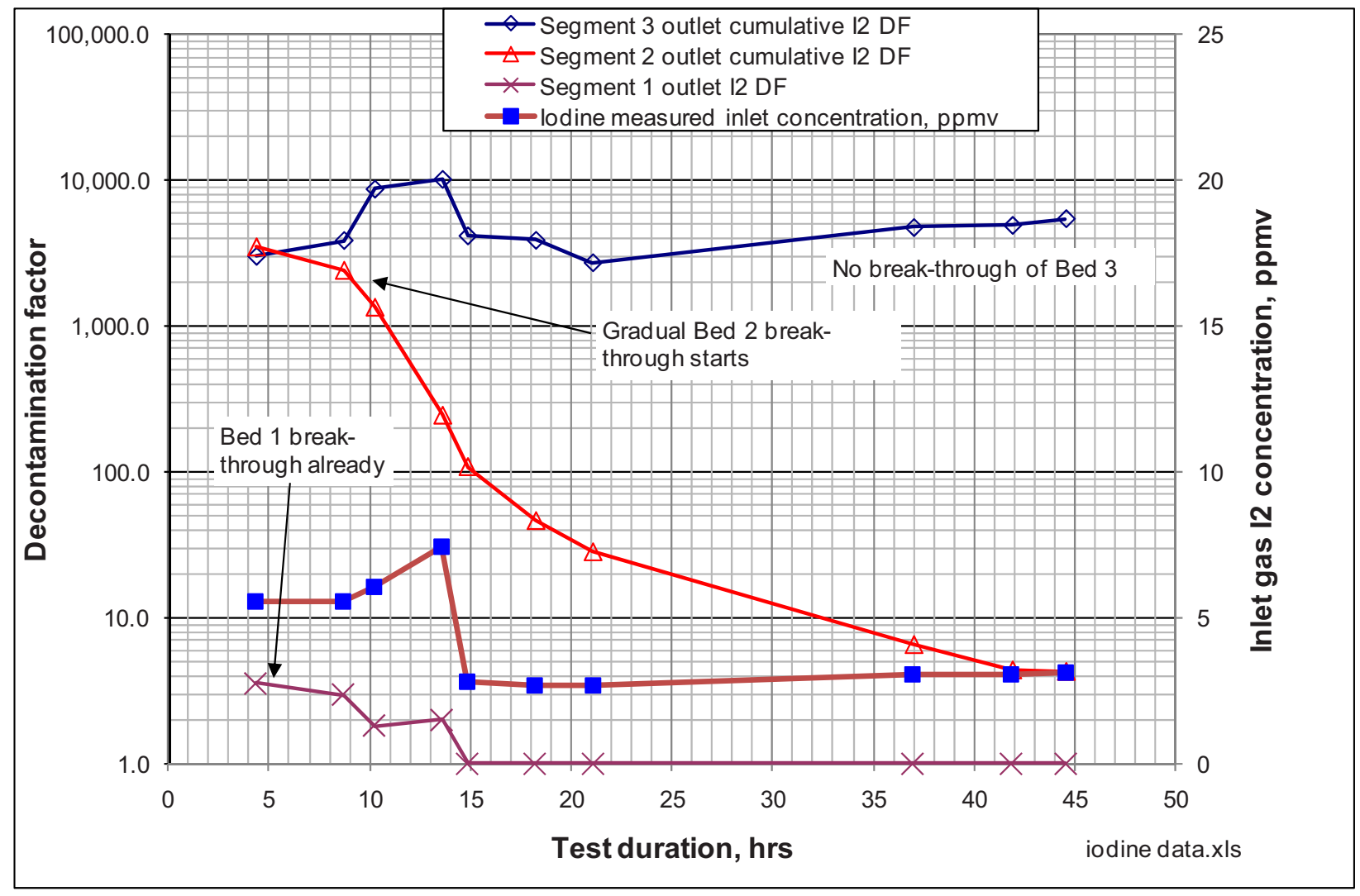

Figure 4-6. Test 1AgZ-LP iodine sorption results.

\subsubsection{Test 2 Methyl lodide Sorption Results}

Figure 4-7 shows how the inlet methyl iodide concentration and the bed sorption efficiencies (reported DFs) trended for the duration of Test 2. Summary results include:

- The measured inlet methyl iodide levels ranged between about 17-20 ppm for most of the test duration. 


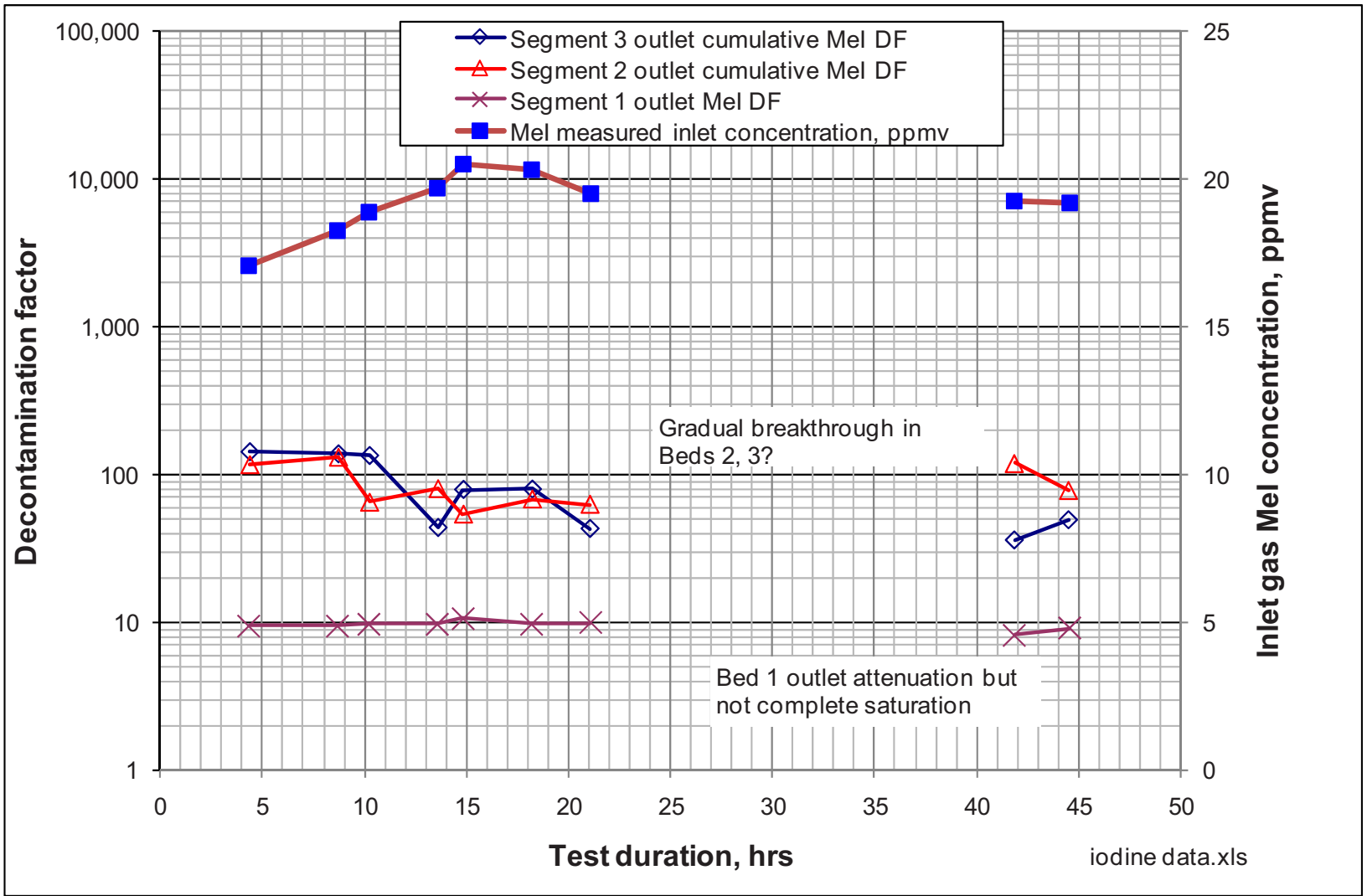

Figure 4-7. Test 1AgZ-LP methyl iodide sorption results.

- After about 45 hours of test operation, a typical breakthrough trend for Bed 1 is not evident. However, the Bed 1 DF was consistently low at about 9-10. This is consistent with the theory that, along with possible methyl iodide sorption, there may be other reactions besides sorption that affect the bed outlet methyl iodide measurements.

- One might speculate that gradual breakthrough of methyl iodide may have started occurring for Beds 2 and 3 starting about hour 10. This speculation is not supported by the relatively equivalent measurements at the test end. The Bed 2 and total Bed 3 cumulative DFs ranged between about 400 to over 1,000 for most of the test duration.

\subsection{Test 3 lodine Sorption Results}

Figure 4-8 shows how the inlet iodine concentration and the bed sorption efficiencies (reported as decontamination factors, DFs) trended for the duration of Test 3. For Test 3, the inlet iodine concentrations were much higher, and varied from sample period to sample period. No methyl iodide was used in this test, as the on-line GC was off-line for repairs. 


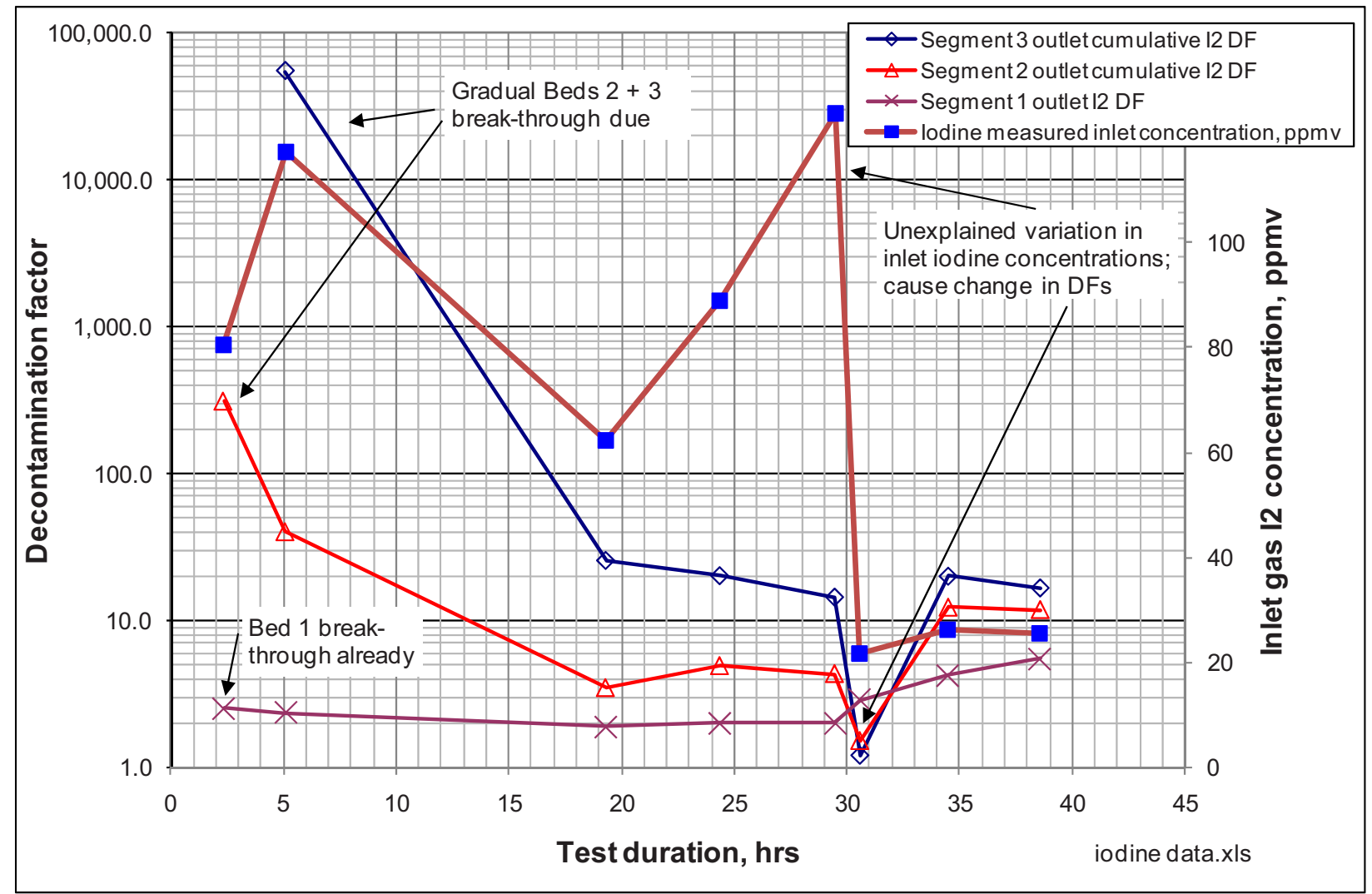

Figure 4-8. Test 3AgZ-LP iodine sorption results.

This test provided the following results:

- The inlet iodine levels ranged between about 60 to $125 \mathrm{ppm}$ during the first first 30 hours, and then dropped to between 22-26 ppm for the last 9 hours. This was the first test done at such high inlet iodine concentrations, and is not readily explained.

- The high iodine concentrations seem to have stretched out the mass transfer zone so that, by the first sample period at about hour 2, the Bed 1is already significantly saturated, and the Bed 2 is also breaking through. The first Bed 3 sample occurred at about hour 5. By the next sample period (about hour 19) Bed 3 has broken through too. This gap occurred in the sample periods while the test system continued to run overnight unattended. (In hindsight, we should have shut down overnight or else continued to sample overnight to better track the sorption performance.)

- The Bed 3 outlet cumulative DF exceeded 50,000 at hour 5. This, combined with the breakthrough of beds 1 and 2 by about hour 2, indicate that the MTZ is greater than 2 inches long, but less than 4 inches long.

- The DF for Bed 1 never dropped to 1, indicating that, with such high concentrations, there was continued but slow sorption throughout the test duration. This seems possible considering the large driving force of the high gaseous iodine concentrations.

- The DFs seemed responsive to the changes in inlet iodine concentrations, evidenced by the drop in DFs at about hour 31 when the inlet iodine concentration dropped dramatically. 
- The Bed 1 iodine loading reached $40 \mathrm{~g}$ iodine per $100 \mathrm{~g}$ sorbent, and the Ag utilization exceeded a whopping $200 \%$. This unlikely condition appears to have occurred due the high iodine concentrations and the high physisorption of iodine on the sorbent. The post-test purge data supports this statement because the outlet iodine concentrations were much higher than the iodine concentrations in the purge gas from the prior, lower-concentration iodine tests. The Bed 1 purge gas ranged from 2-3 ppm iodine, about 3-10x higher than the iodine levels during purging the prior tests. The bed 2 and 3 purge gas iodine levels ranged from 0.7 to $1.1 \mathrm{ppm}, 2-100 \mathrm{x}$ higher than the bed 2 and 3 purge gas levels during purging the prior tests.

- The results of this test indicate different sorption conditions (longer MTZ, more physisorption) than the prior tests, but still show that with proper sorbent design (in particular, a deeper bed to contain the deeper mass transfer zone and greater amounts of iodine) efficient iodine sorption is not only possible but favored, with such a high driving force from the high gaseous iodine concentrations. 
Deep Bed lodine Sorbent Testing FY 2011 Report

August 31, 2011

This page blank 


\section{CONCLUSIONS AND RECOMMENDATIONS}

Additional sorption tests are in progress. These data can be reported in a future revision of this report or in another report.

The issue of identifying and speciating other iodine species that may form in or on the sorbent has not yet been resolved. In terms of overall sorbent bed performance this may not be significant, as long as the target iodine control efficiencies are achieved. However, more insight can be provided if an on-line mass spectrometer analysis capability can be developed in the next fiscal year. Additional insight can be provided by performing tests under identical conditions but with and without the addition of methyl iodide.

Over the past 3 years, we have explored a full range of inlet iodine and methyl iodide concentrations ranging from $\sim 100 \mathrm{ppb}$ to $\sim 100 \mathrm{ppm}$ levels, and shown adequate control efficiencies within a bed depth as shallow as 2 inches for lower concentrations and 4 inches for higher concentrations, for the AgZ-type sorbents. We are now performing a limited number of tests in the NC-77 sorbent from SNL. Then we plan to continue to (a) fill in data gaps needed for isotherms and dynamic sorbent modeling, and (b) test the performance of additional sorbents under development. 
Deep Bed lodine Sorbent Testing FY 2011 Report

August 31, 2011

This page blank 


\section{REFERENCES}

EPA 2010a Protection of Environment: Chapter I--Environmental Protection Agency (Continued). Part 190_Environmental Radiation Protection Standards for Nuclear

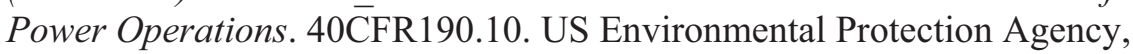
Washington, DC.

EPA 2010b Environmental Protection Agency: Part 61--National Emission Standards for Hazardous Air Pollutants. Subpart H-National Emission Standards for Emissions of Radionuclides Other Than Radon from Department of Energy Facilities. 92 Standard. 40CFR61.92. US Environmental Protection Agency, Washington, DC.

Haefner 2009 Haefner, D. R., and N. Soelberg, "Experimental Sorption Testing of Elemental Iodine on Silver Mordenite,” INL/EXT-09-16837, September 2009.

Haefner 2010 Haefner, D. R., and T. Watson, "Summary of FY 2010 Iodine Capture Studies at the INL," INL/EXT-10-19657, August 2010.

INL 2011

Jubin 2011

"Gas Phase Iodine Capture Methods for Non-Radioactive Materials," Laboratory Instruction 1287-070CFA, Revision 3, eCR No. 583874, February 16, 2011.

Jubin, Bob, et al, "Assessments and Options for Removal and Immobilization of Volatile Radionuclides from the Processing of Used Nuclear Fuel," FCR\&D-SWR2011-000305, 31 August 2011.

NRC 2011 Chapter 10, Energy: Part 61--Licensing Requirements for Land Disposal of Radioactive Waste. 41 Protection of the General Population from Releases of Radioactivity. 10CFR20.10.61.41. US Nuclear Regulatory Commission, Washington, DC.

Pantano 2011 Pantano, Carlo, Tom Thomas, Jack Watson, and Chris Phillips, "FCR\&D Off-Gas Sigma Team Peer Review, June 23-24, 2011.

Soelberg 2008 Soelberg, Nick, Mike Abbott, Daryl Haefner, and Bob Jubin, "Gaseous Fission Product Emissions Control During Spent Nuclear Fuel Recycling," $235^{\text {th }}$ ACS National Meeting and Exposition, New Orleans, LA, April 6-10, 2008 .

Soelberg 2010 Soelberg, Nick, Veronica Rutledge, Tony Watson, Daryl Haefner, and Jack Law, "Test Plan for Iodine Sorption Studies: FY 11," unpublished Idaho National Laboratory document, December 13, 2010. 